\title{
"BashudaivaKutumbakkam"- The entire world is our home and all living beings are our relatives. Why we need to worry about climate change, with reference to pollution problems in the major cities of India, Nepal, Bangladesh and Pakistan
}

\author{
Medani P. Bhandari \\ Akamai University, Hilo, Hawaii, USA and Sumy State University, Ukraine
}

Correspondence: Prof. Medani P. Bhandari, Email medani.bhandari@gmail.com

Received: February 20, 2019 | Published: March 07, 2019

Copyright@ 2019 Bhandari. This is an open access article distributed under the terms of the Creative Commons Attribution License, which permits unrestricted use, distribution, and reproduction in any medium, provided the original author and source are credited.

\begin{abstract}
In this interview format opinion paper, Professor Medani P. Bhandari, directly or indirectly reveals the interconnected impact of geographical, and socio-cultural environment on personal motivation building. As such Prof. Bhandari tells the story of why and how he became interested in the conservation of nature and natural resources, what was the problems and how he overcome and continuously working on the same track with same focus in his entire life; however, it might be the story of each environmentalist who have tried to continue environment conservation action and activism and academic scholarships together. Prof. Bhandari is a lifelong conservationist, expert of climate change impact, social empowerment and educationalist, who has devoted his entire life for the conservation of nature and social services. This true story tells how personal background makes people's perceptions on nature and society and what role a spiritual / tradition, Indigenous knowledge can motivate himself or herself to devote on conservation of nature and social empowerment. Prof. Bhandari shares why he thinks "VashudhivaKuttumbakam" the entire planet is our home and all living beings are our relatives. He also shares the essence of education, he uses the term EDUCARE- education for life. In this interview Prof. Bhandari explains the severity of current environmental impact on human and other living beings and explicate how and why we need to worry. He shows the evidences of negative impact of climate change on cities and how dangerous is the pollution condition in major cities of India, Pakistan, Bangladesh and Nepal. Prof. Bhandari has published about 50 papers on international journals, published four books and poems volumes.A brief biography and contact details of Prof. Bhandari is included at the end of this interview.Prof. Bhandari states "My intention, of life is to pay back; give or contribute to the society in fullest whatever I have, earned, or experienced." Hopefully readers will enjoy reading and will be benefited from this true an intrinsic motivational story with the evidences of scientifically grounded facts. A brief bio of Prof. Bhandari is available at the end of this interview.
\end{abstract}

Keywords: "Vasudhaiva Kutumbakam" (the entire world or earth is your famility); India, Nepal, Bangladesh, Pakistan, South Asia, Government, Climate Change, Environmental Problems, Pollutions, Floods, Landslides, Earthquakes, Cyclones/Storms, Over Population, Water Crisis, Deforestation, Plantation, Mass Media, Delhi, Kathmandu, Dhaka, Karachi, Mountain Everest, Ganges, Sea level, IPCC, IUCN, United Nations, SAARC, ICIMOD.

Q: Prof. Bhandari, thank you for taking the time to speak with us about your career in environmental protection and climate change. These are obviously serious and pressing concerns for people throughout Asia, as well as around the world.

Thank you very much for inviting me to discuss and share my experience in this very critical issue. Environment protection and climate change is a global concern. It is established notion that major environment concern / problems are Ozone layer depletion; Global warming; and Loss of biodiversity. As such each of these problems has negative impact on life on earth. For example, Ozone layer depletion has Effects on Human and Animal Health (i.e. eye diseases, skin cancer, infectious diseases); Effects on Human and Animal Health (increases radiation could change species composition, or change in plant forms); Effects on Aquatic Ecosystems (affect the distribution of phytoplankton's, reproduction system alteration); Effects on Bio-geo-chemical Cycles (affect terrestrial and aquatic bio-geo-chemical cycles); Effects on Air Quality (can increase both production and destruction of ozone and related oxidants such as hydrogen peroxide-which can have direct adverse effects). Similarly, another problem is global warming which more severe. Evidence shows that Global temperature increase 0.3-6 within last 100 years, and major contributor for this change are we the human. Globe is warming, and main cause is greenhouse gases (GHG) causing global warming is carbon dioxide. The evidence of global warming is rise in global temperature and rise in sea level which ultimately affecting ecosystems of the planet. Kleinschmidt stated, "Documented increases in global air and sea temperatures over the last century have demonstrated unequivocally that our planet is warming. Most climatologists agree that the warming trend will continue, and at an accelerating pace unless the causes of global warming are addressed immediately. This reality, and the urgent need for action, is finally being recognized by society and governments around the world." 
There is inevitable relationship between agriculture and environment [the surroundings or conditions in which a person, animal, or plant lives or operates ${ }^{2}$, it also covers climatic condition, its pattern and change. Human existent and civilization began with the development of agriculture which fully relies on climatic variations of specific location of Earth Surface. All of us have been witnessing the variation and change on climate one way or another. With no doubt, we, the humans are directly or indirectly responsible and have been contributing for this climate change, wherever we live or do; however, the degree of contribution and impact may vary. As a matter of fact, many initiatives and steps have been taken at the international to individual levels (various international treaties, policies, actions, etc.). However, still there are unmeasured and unexplored issues on "how climate change has already impacted and will affect the lives support ecosystems". On the other hand, there are also people who actually do not support the following statements from Pachauri et al. ${ }^{3}$ :

"Human influence on the climate system is clear, and recent anthropogenic emissions of greenhouse gases are the highest in history. Recent climate changes have had widespread impacts on human and natural systems. Warming of the climate system is unequivocal, and since the 1950s, many of the observed changes are unprecedented over decades to millennia. The atmosphere and ocean have warmed, the amounts of snow and ice have diminished, and sea level has risen."

"Anthropogenic greenhouse gas emissions have increased since the pre-industrial era, driven largely by economic and population growth, and are now higher than ever. This has led to atmospheric concentrations of carbon dioxide, methane and nitrous oxide that are unprecedented at least the last 800,000 years. Their effects, together with those of other anthropogenic drivers, have been detected throughout the climate system and are extremely likely to have been the dominant cause of the observed warming since the mid-20th century."

In my opinion, the people or group, only externally, oppose the statement "the climate change is occurring due to anthropogenic disturbance in natural environment" in the inner heart they know, the fact that, globe is warming and we human are responsible. I think, every one of us have witnessed or experienced the change in global environment or heard about the recent past and current situation of our environment.

Q: We would like to start off with asking you about how you became interested in protecting the environment in the first place? What led you to making this the focus of your academic studies and your eventual long-term career?

How I became interested protection of environment?? This is very important question. To respond this, I need to go back to my childhood.

I born in the most beautiful place of the planet, at the bank of the 'HyatungJharana' water fall (One of the highest water falls in South Asia with 365-meter height situated in the Eastern, Nepal. It is located at the confluence of VDC Ishibu and Samdu, Terathum District), a very remote village. I grew up listening of the music of water falls and rivers. At the age of one and half, I was taken to my Grandparent (mother side) to Hwaku, where I had direct view of Tamor River, one of the tributary of the Saptakoshi River. My Grandparent's house is located at the top of the Hill, from where one can see the several tops of Mountains, two Evergreen Rivers Phoguwakhola and Iwakhola and Tamor River where Phoguwa and Iwa merge.

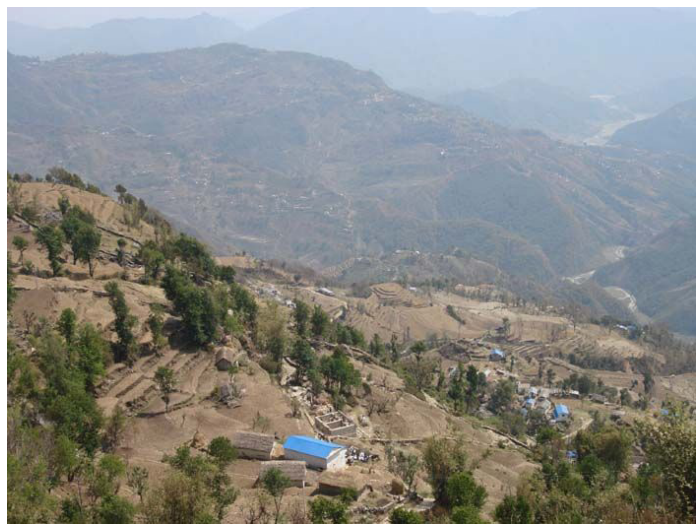

A distance few of type of landscape of my play area of childhood. Photo source: Facebook, Khusi Rai Facebook Photos ${ }^{4}$

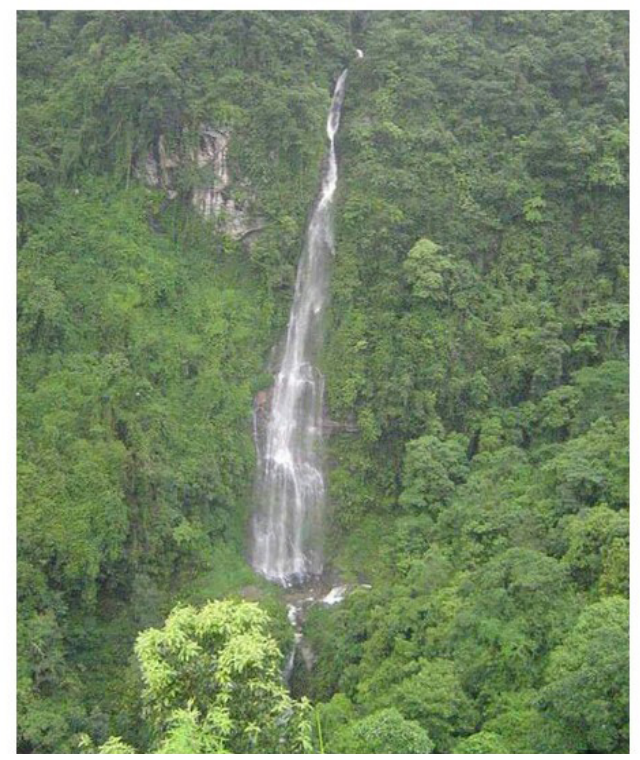

One of the highest water falls in South Asia with 365-meter height situated in the eastern part of Nepal. It is renowned as 'HyatungJharana' in local terms. Photo source: Facebook ${ }^{5}$

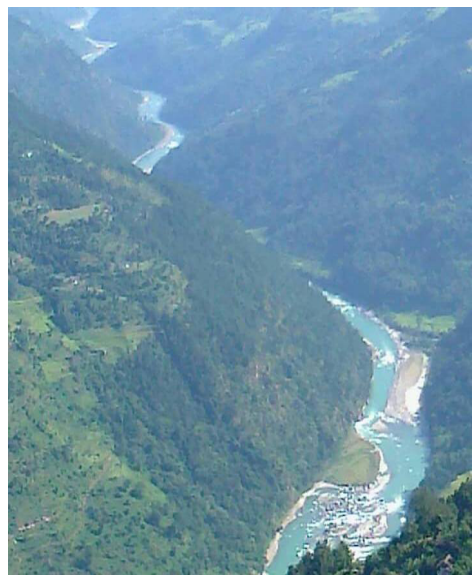

The daily view of my childhood- the Tamor River of Nepal. Photo Source: Facebook $^{5}$
Citation: Bhandari MP. "BashudaivaKutumbakkam"-The entire world is our home and all living beings are our relatives. Why we need to worry about climate change, with reference to pollution problems in the major cities of India, Nepal, Bangladesh and Pakistan. Adv Agr Environ Sci. (2019);2(I): 8-35. DOI: 10.3088I/aaeoa.000I9 
My grandparent Late Abhikesher and Jalapa Devi Gautam raised me in the spiritual environment. They taught me to consider all living creatures (plant and animal) and non-living objects (like stone, soil, air, and cloud) as deities, creation of God. I learn to appreciate the nature, before I learn to speak and walk. I grew in the primitive kind of environment if we compare the current developed world context.
I think the base of my orientation towards conservation of nature and nature is the culture, which taught me to appreciate nature. According to Hindu mythology, each living and non-living structure are interconnected and supportive to each other. For example, there are millions of gods and goddesses and each of them have association with animal and plant.

Table I Plants associated with dieties

\begin{tabular}{lll}
\hline Name of God/Goddess & Symbol & Vehicle / plant associated \\
\hline Goddess Bagabati & goddess of power & Lion/ tiger Red flowering tree \\
Lord Shiva & god of law/ Protection & Bull /Poisonous plant \\
Vishnu & god of Creation & Stroke (Garuda)/ Ficusreligiosa \\
Saraswati & Wisdom and knowledge & Swan and peacock/ Lotus \\
Laxmi & Goddess of wealth & pair of Elephant/ Lotus \\
Ganesh & the combination of power Wealth and wisdom & Rat/ Sandilondectilon \\
Yama & God of death & Wild water buffalo/ Bamboo \\
\hline
\end{tabular}

A similar principle may apply with other religious mythologies (Baha'i, Buddhism, Christianity, Daoism, Hinduism, Jainism, Judaism, Islam, Shinto, Sikhism and Zoroastrianism etc.) in different form.

The first thing I learned from the childhood was the appreciation to "whatever we see, and feel, including, air, the surrounding, trees, birds, animal and structure of rock, terrain, land escape", because they were all included in the daily morning prayers. Some of them include ${ }^{6}$ :

Om BhadramKarnebhihShrinuyama Deva BhadramPashyemakshabhiryajatrah /

SthirairangaistushtuvaSastanubhirvyashemahi DevaHitam Yadayuh//

Meaning: Gods, may we with our ears listen to what is good, and with our eyes see what is good, ye Holy Ones. With firm limbs and bodies, may we extolling you attain the term of life appointed by the Gods.

Om Aa No

BhadrahKratavoYantuVishvatoadabdhasoAparitasaUdbhidah/

Deva No YathaSadamidvridheAsannaprayuvoRakshitaro Dive-Dive//

Meaning: May powers auspicious come to us from every side, never deceived, unhindered, and victorious. That the Gods ever may be with us for our gain, our guardians' day by day unceasing in their care.

[Om Dyauh Shantirantariksha Shantih Prithivi Shantirapah Shantiroshadhayah Shantih/

Vanaspatayah Shantirvishvedevah Shantirbrahma Shantih Sarva Shantih Shantireva Shantih Sa Ma Shantiredhi//]

Meaning: "May peace radiate there in the whole sky as well as in the vast ethereal space everywhere. May peace reign all over this earth, in water and in all herbs, trees and creepers. May peace flow over the whole universe. May peace be in the supreme being Brahman. And may there always exist in all peace and peace alone."

Most probably, repetedly reciting such prayers, might have given some inner intrinsic motivation to me to devote for the conservation of nature and natural resources.
I, think, in the scholarly term, the home, tradition, culture and belief help to build my mindset to appreciate, protect nature and also motivate others to do the same. While, I was still in forth grade my uncle (maternal), Ram Chandra Gautam, who was a school teacher, begin to teach me about the world culture and religions and how they all have motive of public welbeing. The first profounding concept I got enternalize was "Vasudhaiva Kutumbakam" (the entire world or earth is your famility).

I think the lession and essence of "Vasudhaiva Kutumbakam" begin to build within my inner self, on which I strongly follow and believe. This philosophy is written in Hitopadesha, 1.3.71: 'ayamnijahparovetigananalaghuchetasam; udaracharitanamtuvasudhaivakutumbhakam' [Meaning: The distinction "This person is mine, and this one is not" is made only by the narrow-minded (i.e. the ignorant who are in duality). For those of noble conduct (i.e. who know the Supreme Truth) the entire world is one family (one Unit).]. Be detached, be magnanimous, lift up your mind, enjoy the fruit of .... Freedom (Maha Upanishad 6.71-75).

When I was at high school, I studied world religions and culture. I was so amazed when, I found that, the purpose of all traditions (including indigenous), cultures, religions were the same "this earth belongs to all of us and human task is to protect the mother earth and fellow living and non-living beings, who help before our birth to death and even after death".

Here I would like to list some of important quotations from the great epics on environment conservation issues ${ }^{7}$ :

Christianity:

"The Bible: No one lighting a lamp puts it under a basket, but on a lampstand and it gives light to all in the house. In the same way, let your light shine before others, so that they may see your good works and give glory to your Father in heaven". -The Bible (Matthew 5: 15-16) (page 37).

"Nature and Nature's laws lay hid in night:

God said "Let Newton be!" and all was light". (Alexander Pope around 1718) (page 18). 
Islam:

"O children of Adam! . .. eat and drink: but waste not by excess for Allah loveth not the wasters. -Holy Qur'an, Surah 7:31" (page 3).

Jain:

"Ahimsa-this is a fundamental vow and runs through the Jain tradition like a golden thread. It involves avoidance of violence in any form, through word or deed, not only to human beings but to all nature. It means reverence for life in every form including plants and animals. Jains practice the principle of compassion for all living beings at every step in daily life. Jains are vegetarians". -The Jain Statement on Ecology (page 15).

Daoism:

"Daoism has a unique sense of value in that it judges affluence by the number of different species. If all things in the universe grow well, then a society is a community of affluence. If not, this kingdom is on the decline" -The Daoist statement on ecology (chapter 10) (page 23).

Chinese medicine has traditional root and philosophy: "Its worldview is based on belief in the Dao-the nature of the universe-which is best described in a famous series of verses in the Dao De Jing, written in the fourth century B.C.:

The Dao gives birth to the One:

The One gives birth to the Two:

The Two gives birth to the Three:

The Three gives birth to every living thing.

All things are held in yin and carry yang:

And they are held together in the qi of teeming energy.

The One is the universe, which gives birth to the two primal forces of yin and yang, which are the natural forces of opposites. Yin, for example, is cold, wet, winter, female, and earth, while yang contrasts to this by being hot, dry, summer, male, and heaven". (page 26).

Baha'i:

"Baha'i scriptures teach that, as trustees of the planet's vast resources and biological diversity, humanity must seek to protect the "heritage [of] future generations"; see in nature a reflection of the divine; approach the earth, the source of material bounties, with humility; temper its actions with moderation; and be guided by the fundamental spiritual truth of our age, the oneness of humanity. The speed and facility with which we establish a sustainable pattern of life will depend, in the final analysis, on the extent to which we are willing to be transformed, through the love of God and obedience to His Laws, into constructive forces in the process of creating an everadvancing civilization" (page 76).

Buddhism: Nature as a way of life

"The Buddha commended frugality as a virtue in its own right. Skillful living avoids waste and we should try to recycle as much as we can. Buddhism advocates a simple, gentle, nonaggressive attitude toward nature-reverence for all forms of nature must be cultivated" (page 81).

"We need to live as the Buddha taught us to live, in peace and harmony with nature, but this must start with ourselves. If we are going to save this planet, we need to seek a new ecological order, to look at the life we lead and then work together for the benefit of all; unless we work together no solution can be found. By moving away from self-centeredness, sharing wealth more, being more responsible for ourselves, and agreeing to live more simply, we can help decrease much of the suffering in the world" (page 82).

Judaism:

"Love your neighbor as yourself”, (Lev. 19:18) (page 113).

"When God created Adam, he showed him all the trees of the Garden of Eden and said to him: "See my works, how lovely they are, how fine they are. All I have created, I created for you. Take care not to corrupt and destroy my universe, for if you destroy it, no one will come after you to put it right." (Ecclesiastes Rabbah 7) (page 111). In Jewish sources, the rationale for humanity's obligation to protect nature may be found in the biblical expression, "For the earth is Mine" (Lev. 25:23). The Bible informs us that the Earth is not subject to man's absolute ownership, but is rather given to us "to use and protect" (Gen. 2:15)" (page 111).

Shintoism:

"Shinto regards that the land, its nature, and all creatures including humans are children of Kami. Accordingly, all things existing on this earth have the possibility of becoming Kami. ...

The ancient Japanese considered that all things of this world have their own spirituality, as they were born from the divine couple. Therefore, the relationship between the natural environment of this world and people is that of blood kin, like the bond between brother and sister" (page 127).

Sikhism:

"The Sikh scripture, Guru Granth Sahib, declares that the purpose of human beings is to achieve a blissful state and to be in harmony with the earth and all creation" (page 131).

Men, trees, pilgrimage places, banks of sacred streams, clouds, fields.

Islands, spheres, universes, continents, solar systems.

The sources of creation, egg-born, womb-born, earth-born,

sweat-born, oceans, mountains and sentient beings.

He, the Lord, knows their condition, 0 Nanak.

Nanak, having created beings, the lord takes care of them all.

The Creator who created the world, He takes thought of it as well". (466) (page 134).

Zoroastrianism:

"Whoever teaches care for all these seven creations, does well and pleases the Bounteous Immortals; then his soul will never arrive at kinship with the Hostile Spirit.

When he has cared for the creations, the care of these Bounteous Immortals is for him, and he must teach this to all mankind in the material world. -Shayasht ne Shayast (15:6)1

These actions, according to Zoroastrianism, will lead toward "making the world wonderful," when the world will be restored to a perfect state. In this state the material world will never grow old, never die,
Citation: Bhandari MP. "BashudaivaKutumbakkam"-The entire world is our home and all living beings are our relatives. Why we need to worry about climate change, with reference to pollution problems in the major cities of India, Nepal, Bangladesh and Pakistan. Adv Agr Environ Sci. (2019);2(I): 8-35. DOI: 10.3088I/aaeoa.000I9 
never decay, will be ever living and ever increasing and master of its wish. The dead will rise, life and immortality will come, and the world will be restored to a perfect state in accordance with the Will of Ahura Mazda" (Lord of Wisdom) (page 145)

These above listed illustrations clearly indicate that, all world religions appreciate nature and encourage and try to empower human to nourish or contribute to protect the mother earth. The world religions, cultures, traditions and my own surroundings were major motivators for me to devote myself for conservation of nature and natural resources formally or informally. I began to think and act on conservation of nature practically like planting trees, campaigning against hunting birds from the school time.

This intrinsic motivation became more visible and action oriented from 1985. During 1984-1985, I began research on indigenous knowledge and religious believe on plant conservation, particularly the Banyan (Ficusbenghalensis) and Peepal (Ficusreligiosa L) trees as a student of sociology \& anthropology. Hindu people plant these trees on important moments in their lives, like the birth of a child or the dead of a relative. I learned a lot about the importance of trees and how local people are adjusting with nature. In the meantime, I was also fortunate to attend lecture of Indian Environmentalist Sunderlal Bahuguna [is a noted Garhwali environmentalist, Chipko movement leader and a follower of Mahatma Gandhi's philosophy of Nonviolence and Satyagraha]. His topic of lecture was on how we are related to nature and why we have to protect forest. His lecture took me back to my childhood, on the essence of BsudaivaKutumbakam (listed above). My father (late) Loknath Bhandari, always tried to boast my instructive motive. My father was great admirer of Sunderlal Bahuguna, who also called as forester (voluntarily).

In the deep, inner mind, I thought, should do whatever I can. From the childhood, I started to motivate the local people to plant Banyan and Peepal trees as well as other religiously important plant species on their important event of lives. It was not very difficult task to do so, because, they already knew the importance of these trees and broadly forest itself. These species are supposed holly trees in Hindu Mythology, so normally people do not cut these plant species. However, this believe is not very powerful as it was before, but still elder people feel sin if they cut these species.

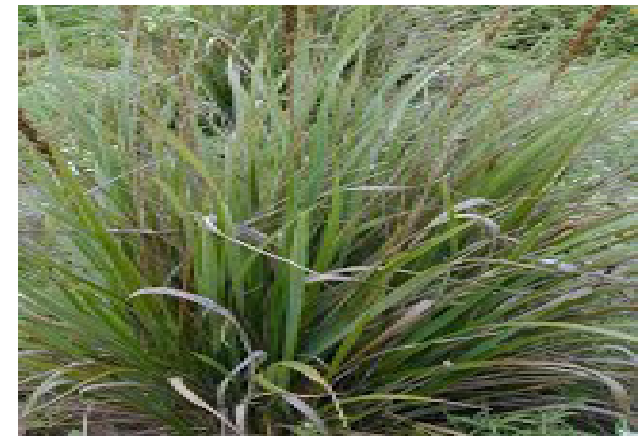

Kush (Dharbham) - EragrostisCynosuroides. It is a tradition of keeping Kush home from centuries. It is scientifically proved that this grass absorbs radiations and bad rays. Even the $\mathrm{x}$-ray can be absorbed by this grass, imagine what else it can do. Desmostachyabipinnata, commonly known in English by the names Halfa grass, big cordgrass, and salt reed-grass, is an Old World perennial grass, long known and used in human history. In India it is known by many names, including: daabh, darbha, kusha, etc. ${ }^{8,9}$

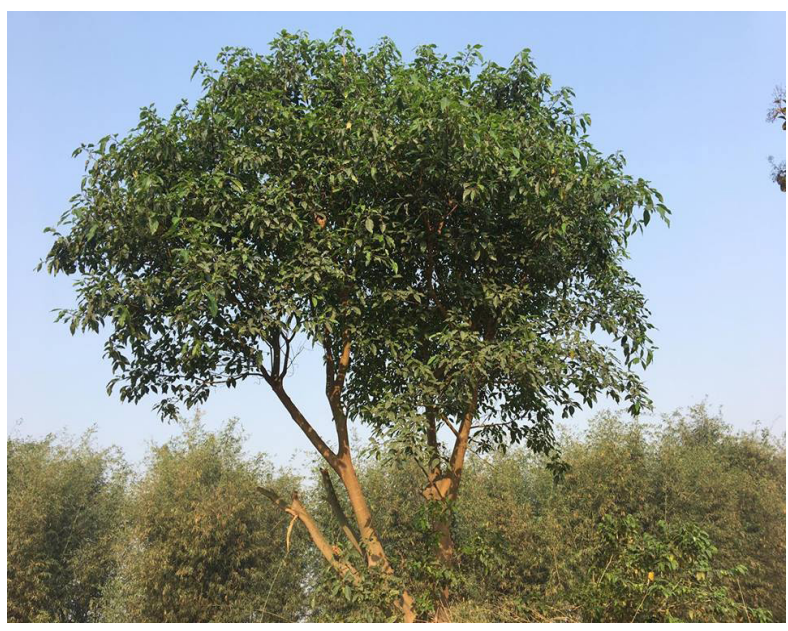

Pterocarpus santalinus (Red Sandal): Pterocarpus santalinus is used in traditional herbal medicine as an antipyretic, anti-inflammatory, anthelmintic, tonic, hemorrhage, dysentery, aphrodisiac, anti-hyperglycaemic and diaphoretic. ${ }^{10}$
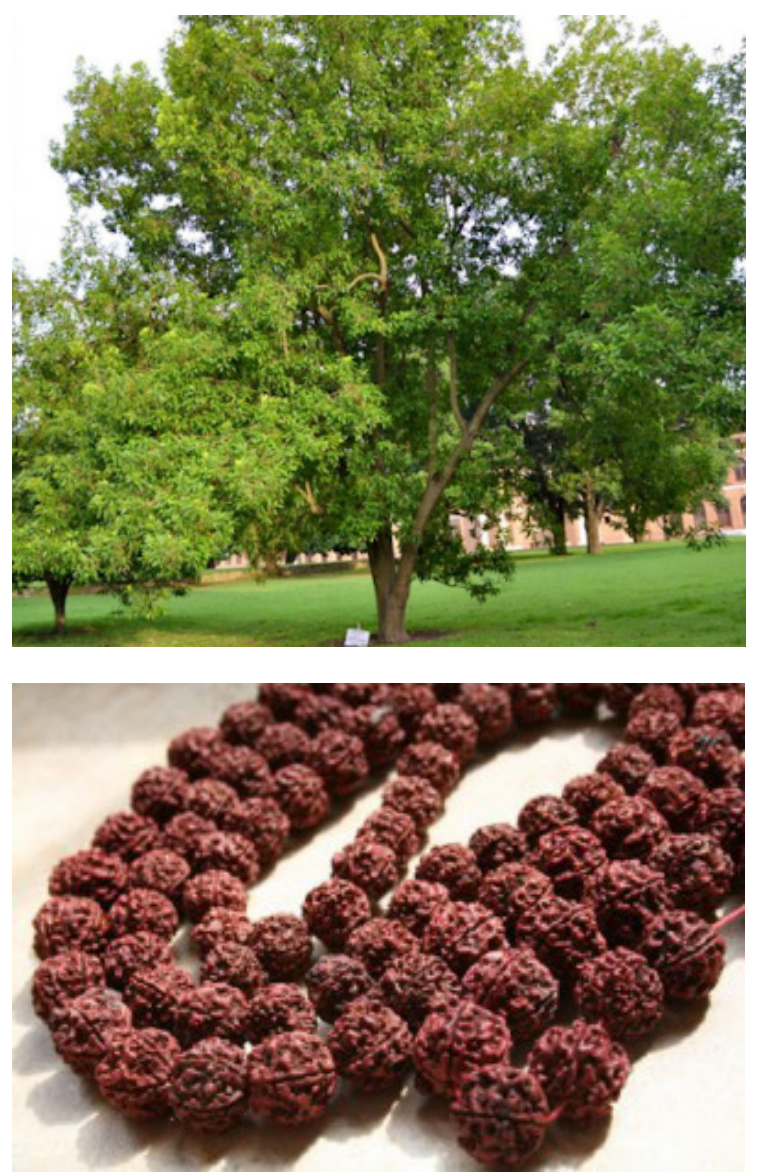

Rudraksha is the seed of a fruit from a tree which belongs to the Elaeocarpus family. " Sanskrit: rudrākșa (Sanskrit: रूद्राक्ष)(“Rudra's [Shiva's] teardrops"), is a seed traditionally used as prayer beads in Hinduism. The seed is produced by several species of large evergreen broad-leaved tree in the genus Elaeocarpus, with Elaeocarpus ganitrus being the principal species. ${ }^{12}$
Submit your Article | www.ologyjournals.com/submit-article

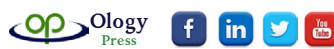

Citation: Bhandari MP. "BashudaivaKutumbakkam"- The entire world is our home and all living beings are our relatives. Why we need to worry about climate change, with reference to pollution problems in the major cities of India, Nepal, Bangladesh and Pakistan. Adv Agr Environ Sci. (2019);2(I): 8-35. DOI: 10.3088I/aaeoa.000 I9 

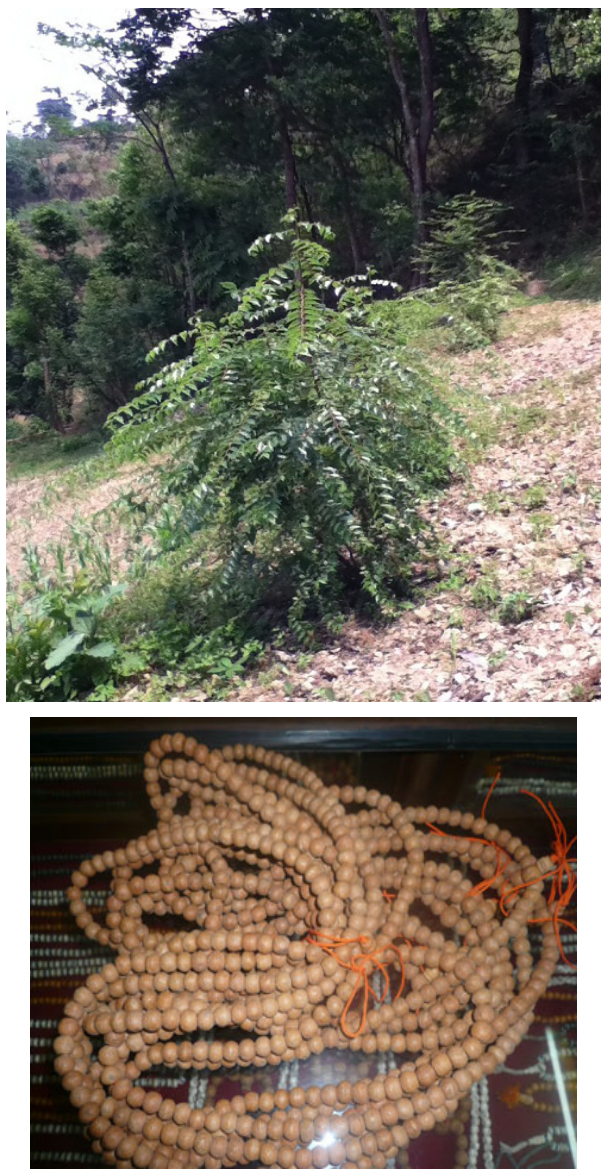

Buddha chitta plant. Ziziphus budhensis, the scientific name for buddha chitta plant is a species of plant in the Rhamnaceae family endemic to the Timal region of Kavreplanchok in Central Nepal. ${ }^{13}$ 'Buddha chitta' or 'ZiziphusBudhensis' is clearly different from the species of 'Ziziphus' already known to grow in Nepal, and it did not match with the Ziziphus species reported to be found in India, Pakistan, Bhutan, Bangladesh, and China. ${ }^{14}$
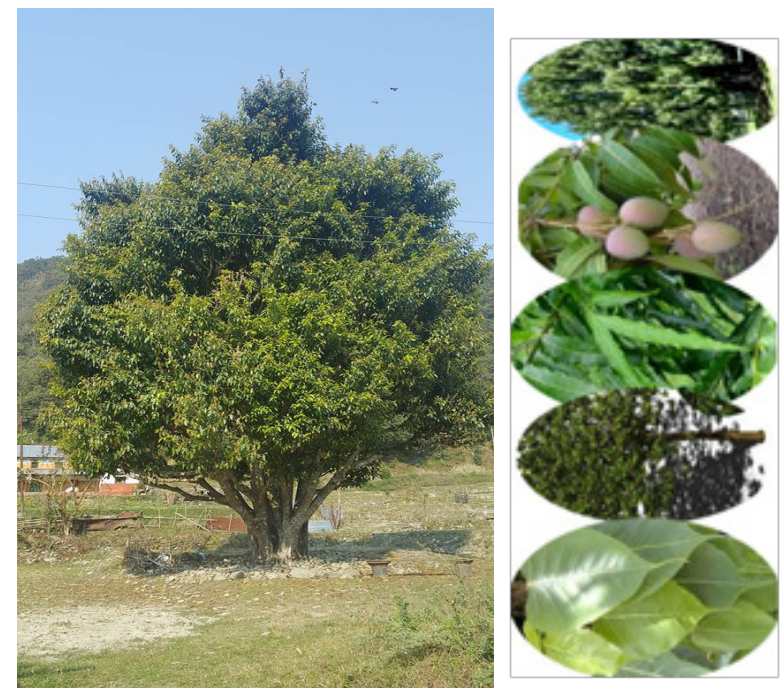

Laxmi Gurung, Pokhara, Nepal and Panchpallav-five secret plants (Peepal, Gular (Ficusracemosa), Ashoka, Mango, Banyan) ${ }^{15}$

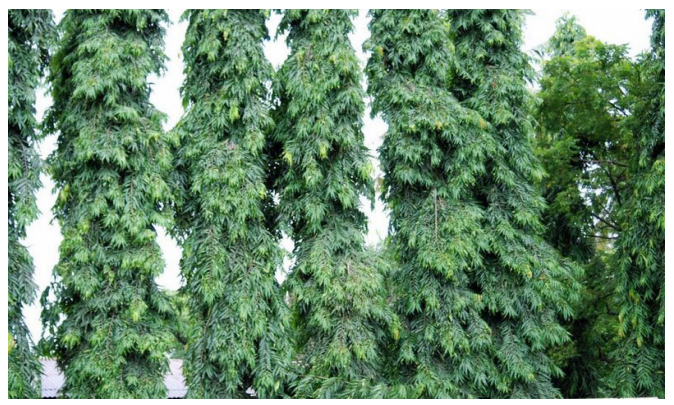

Saracaasoca (the ashoka tree; lit., "sorrow-less") is a plant belonging to the Caesalpinioideae subfamily of the legume family. It is an important tree in the cultural traditions of the Indian subcontinent and adjacent areas. ${ }^{16}$

Banyan and Peepal species are also very good food and habitat source of many bird species. Therefore, these species have a significant importance from the bio-diversity conservational point of view. Banyan and Peepal plant species needs feverish temperature for germination, therefore to establish a nursery is expensive. However, these plants are common and could be found in the old house wall, roof as well as other places where normally birds came and stay or drop their fecal. From the bird's fecal seed spray in different and difficult place, where the seedlings appear. I thought, to establish a nursery by collecting seedlings.

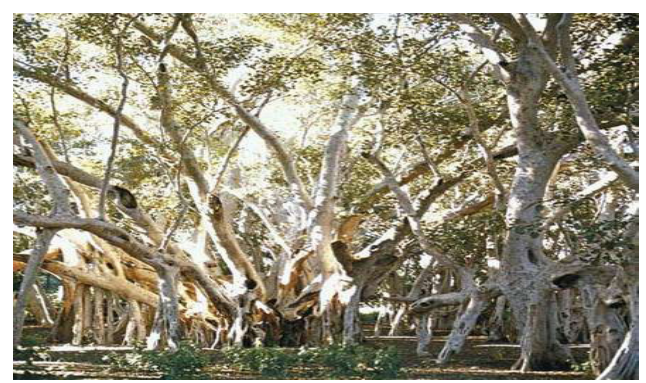

Banyan, (Ficusbenghalensis, or F. indica), unusually shaped tree of the fig genus in the mulberry family (Moraceae) native to tropical Asia. Aerial roots that develop from its branches descend and take root in the soil to become new trunks. The banyan reaches a height up to 30 metres (100 feet) and spreads laterally indefinitely. One tree may in time assume the appearance of a very dense thicket as a result of the tangle of roots and trunks. ${ }^{17}$

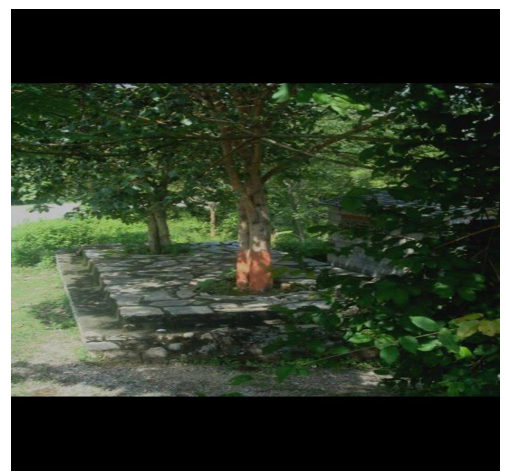

Banyan and Peepal trees in chautari, Photos by Hari Bhandari (Rangeli -3 , Morang, Nepal).These plants (Banyan and Peepal), were planted and nurtured by my grandmother Late Laxmi Devi Bhandari for the memory of her son Late Lok Nath Bhandari (my father, who passed on his 40s.). She arranged marriage of the trees when they reached at the age of II.There is still such tradition to
Citation: Bhandari MP. "BashudaivaKutumbakkam"-The entire world is our home and all living beings are our relatives. Why we need to worry about climate change, with reference to pollution problems in the major cities of India, Nepal, Bangladesh and Pakistan. Adv Agr Environ Sci. (2019);2(I): 8-35. DOI: 10.3088I/aaeoa.000I9 
plant the trees for the memory and for peace of loved one soul.

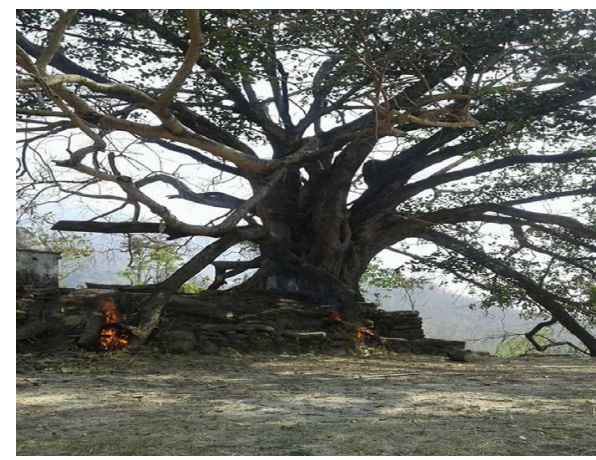

Banyan tree in Mountain Source: Khusi Rai , Facebook photos ${ }^{4}$

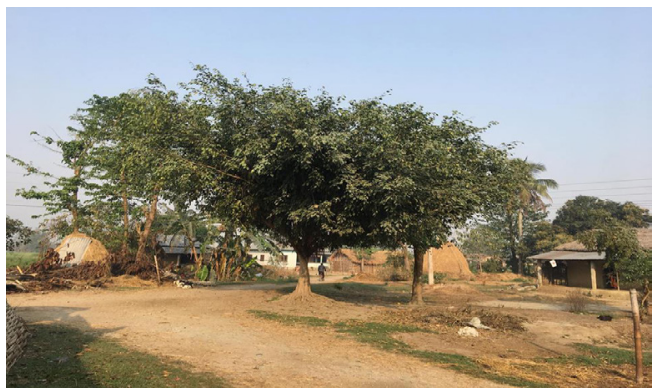

Bar and Peepal tree Photos by Hari Bhandari (Rangeli -3, Morang, Nepal)

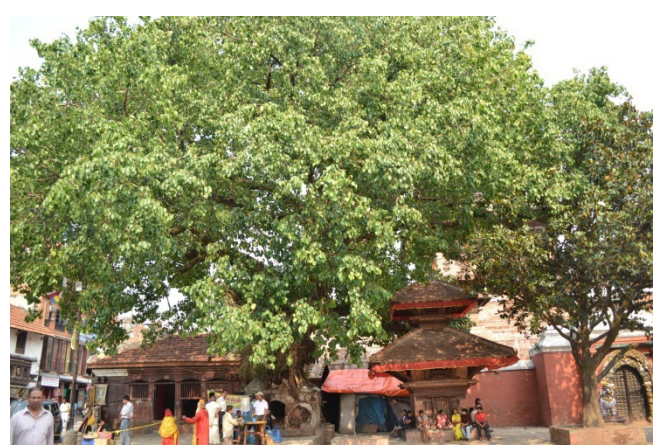

[The Ficus religiosa tree is considered sacred by the followers of Hinduism, Jainism and Buddhism. In the Bhagavad Gita, Krishna says, "I am the Peepal tree among the trees, Narada among the sages, Chitraaratha among the Gandharvas, And sage Kapila among the Siddhas. ${ }^{18,19}$

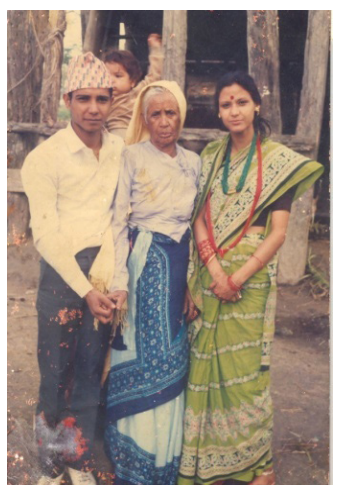

In Picture Grandmother Late Laxmi Devi Bhandari (in middle -on the left Prajita and on right Medani)

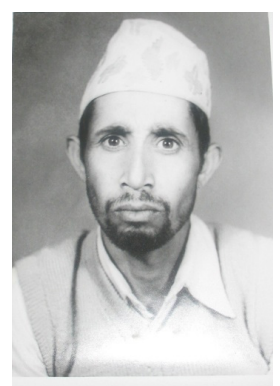

My father Late Loknath Bhandari, who passed away at the age of $40 \mathrm{~s}$. He always incoraged me to concentrate on the theme of BasudaivaKutumbakamthrough environment conservation and social empowerment. He was forest protector with nick name with BAN RAJA, the king of forest as well as Master Baje- Teacher -priest for everybody.

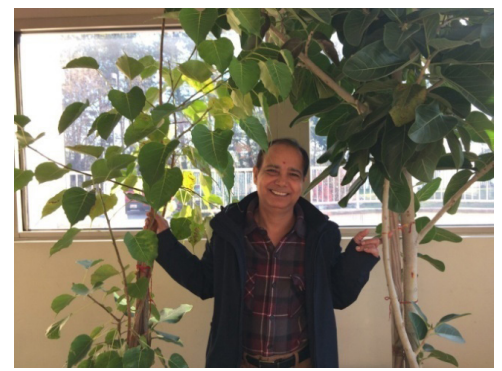

Dr. Medani P. Bhandari at the Hindu Temple of Metropolitan Washington, Photo curtesy Kelsey Johnson (3/10/20/8) on the right side Peepal and on the left side Bunyan. These plants are considered as secret as deities so, these plants are kept on the temple doors.

I along with Miss Prajita started to collect those plant species by riding wall or wherever we saw the seedlings. Later on, Mr. Pradeep Banskota also joined this work and we manage to establish a nursery in my house as well as in a small land provided by the Biratnagar Municipality. This plant collection created awareness in the Biratnagar City in Nepal and people started to give new name to them like MAD Conservationist.

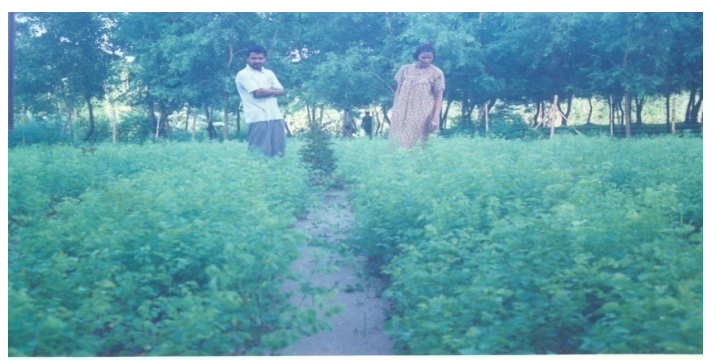

Nursery at bank of Sighiya River, Biratnagar, Morng, Nepal (where and standing with Prajita Bhandari

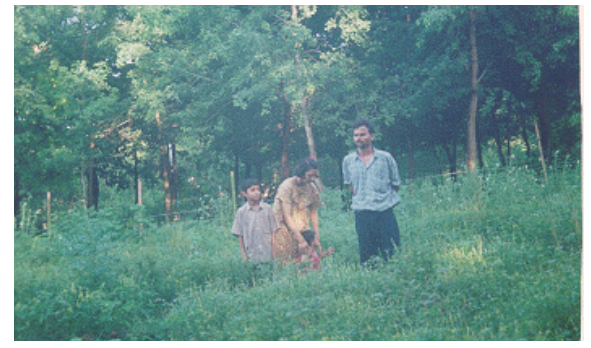

Prajita Bhandari with her kids Prameya and Manaslu with Pradeep Banskota at nursery site
Citation: Bhandari MP. "BashudaivaKutumbakkam"- The entire world is our home and all living beings are our relatives. Why we need to worry about climate change, with reference to pollution problems in the major cities of India, Nepal, Bangladesh and Pakistan. Adv Agr Environ Sci. (2019);2(I): 8-35. DOI: I0.3088I/aaeoa.000I9 


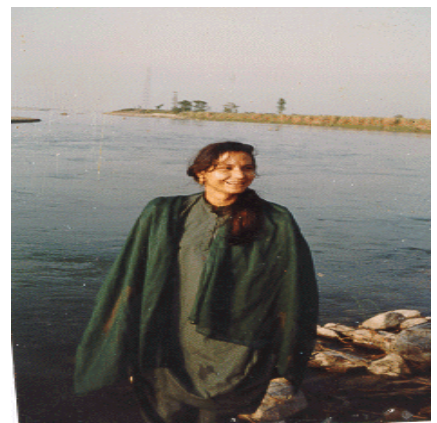

Prajita Bhandari 1987, at Koshi River Bank, dressed with green clothing's during conservation campaign

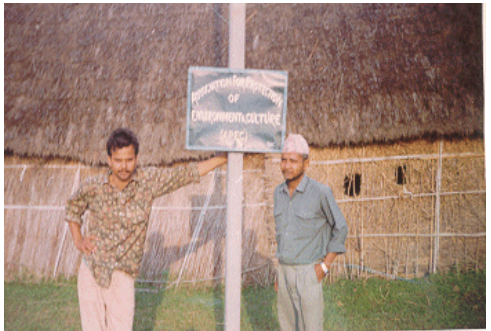

Medani Bhandari with Nepali cap with Pradeep Banskota, outside of KoshiTappu field office-1988
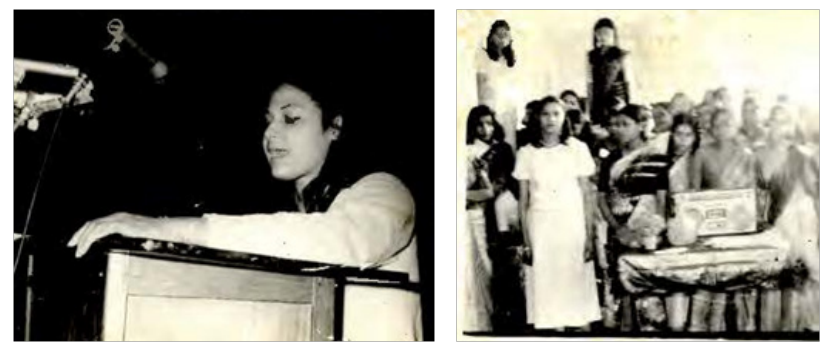

Prajita and her friends in conservation campaign during 1985
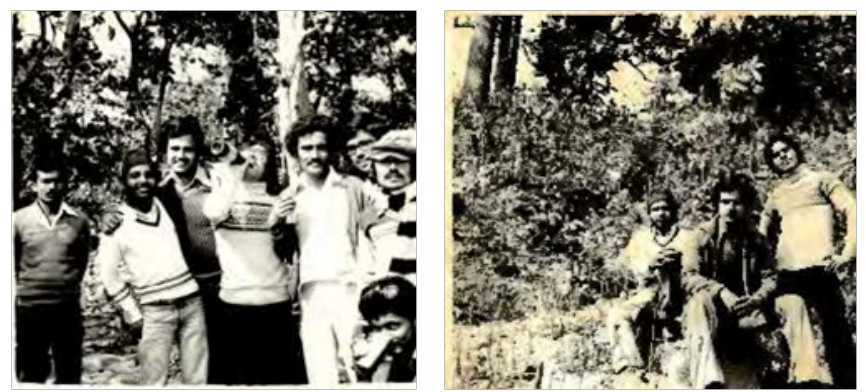

Medani (cap and bear) and friends in consevation campaign during 1985

Firstly, from January 1, 1985, we started survey the marginal land and started plantation as well with available saplings of any plant species. In 1986, we stared awareness campaign on tree plantation and environment conservation. We also started the survey and monitor the forest degradation as well as recording the wild animal, birds and plant species in Jhapa, Udayapur, Dhankuta and Morang districts through interviews with local residence. We also continued to visit same place again and again to monitor the forestry encroachment by the locals illegally and ligulae. In 1987, 10 people from different village development council also joined our group. In this year, I got married to Prajita. People were increasing in the group, so Prajita Bhandari proposed to establish an official forum to work regularly and systematic way. All group members supported his new idea, said that something should be done with it. Together with my wife Prajita, we publicly announced and the decision to devote our lives for conservation of nature and natural resources. In 1988 we cofounded the APEC group (Association for the Protection of Environment \& Culture) in my leadership. ${ }^{20}$ Since then, I have been working in this field together with my wife Prajita. Her father late Dwarika Nath Devkota and mother Durga Devi Devkota, were very supportive financial and socially to us. They were very spiritual personalities. They used to always remind us the meaning of "BasudaivaKutumbakkam". When, we finished all my property in conservation work, she gave me a piece of land, with no rights to sell. They wanted us to survive with any severe situation. When people named us as MAD Conservationist, actually, they were only happy person, "they always told us, do not worry, it is good symbol to reach to the destiny. I would like to acknowledge that, in the conservation mission entire family, were with us and are with us even now. In those time many people stand with us like Narayan Paudel, Bhaktalal Upadhyaya, Krishna Busan Bal, GovindaLuitel, GyanedraBahdur Thapa, Hari Bhandari, Rajan Adhikari Department of National Park, Biratnagar Municipality, KoshiTappu Wildlife Reserve, GovindaPandeya, Hari Gyawali, Gularia Municipality, about 125 Schools of Eastern Nepal, and many more. In reality, without their supports, we would not be able to continue our conservation journey. Wherever, we go, whatever, we do, our major motive of conservation has not changed and will not change.

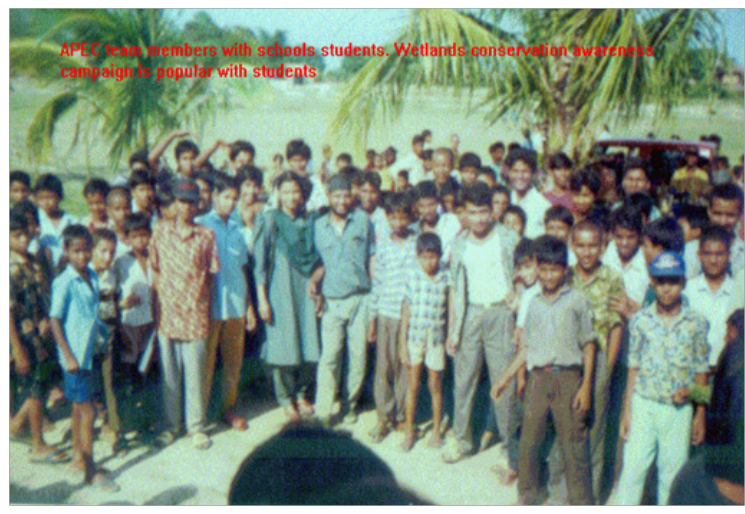

Medani and Prajita Bhandari, in green dresses, with school's team during conservation campaign

The environment conservation movement, including many action projects, were running with to some extend smoothly under my leadership (1985-2000). However, there was a turning point during 2000-2002. In Nepal, there were unseen problems for social activists, environmentalists, etc. (I prefer not to disclose). I felt like I needed to change my direction from core conservationist to academia. The person who helped me to move forward was William Katz (whom I had not seen physically). The Late William (Bill) Katz, from Chicago, used to send many valuable books to schools in Nepal where we were running eco-clubs (it was new initiative then). He always encouraged me to continue conservational work and equally concentrate on
Submit your Article | www.ologyjournals.com/submit-article OP Ology $f$ in $y$ riftess
Citation: Bhandari MP. "BashudaivaKutumbakkam"-The entire world is our home and all living beings are our relatives. Why we need to worry about climate change, with reference to pollution problems in the major cities of India, Nepal, Bangladesh and Pakistan. Adv Agr Environ Sci. (20I9);2(I): 8-35. DOI: I0.3088I/aaeoa.000 I 9 
academic advancement and research. Bill introduced me to the Late Edward Tadashi from Boston. Bill and Edward encouraged me to come to the USA for advance study. They paid my tuition fees and other expenses, while I was at Brandeis University. If they had not supported me, I can't say whether my family would survive. They always encouraged me and appreciated my conservation work in Nepal. Edward also introduced me to several other environmentalists in Boston and Maine. Once I completed my MA in Sustainable International Development, I wanted to continue my studies to receive a $\mathrm{PhD}$. Fortunately, I got in touch with prominent environmental sociologist Dr. Steven R. Brechin (a prominent environmental and organizational sociologist- authors of 100 s of papers and many books) and conducted my PhD under his supervision at Syracuse University, NY, USA. I strongly acknowledge his presence in my academic life.

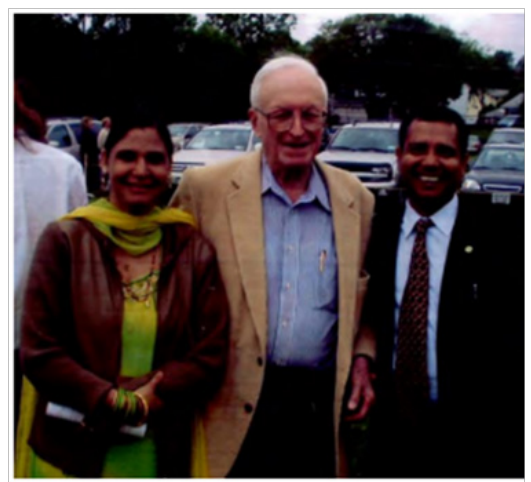

Late Willium Katz in the middle-with Medani and Prajita

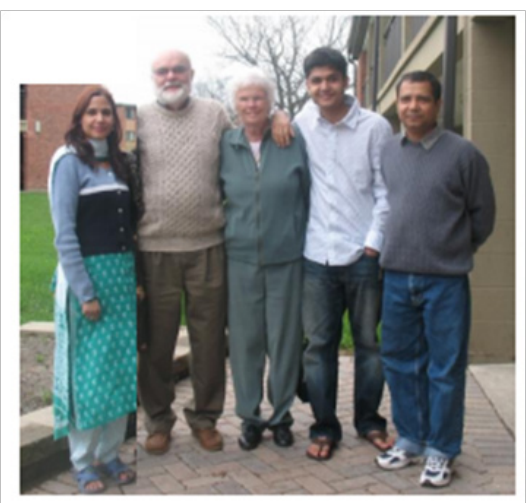

Edward and Lou-Prajita on the left and Prameya and Medani on the right

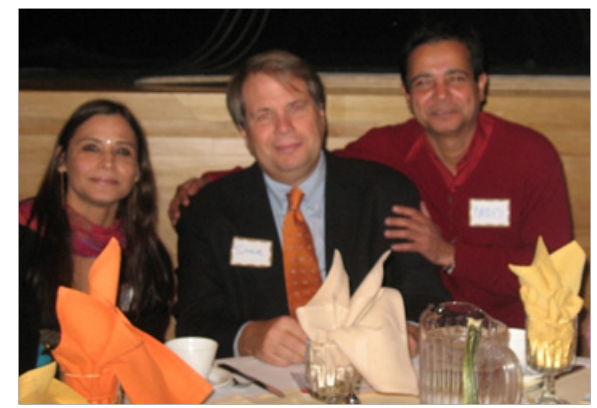

Dr. Steven R. Brechin-with Prajita and Medani
Being from such blessed family and having good scholars' company, I always feel fresh, exited, thrilled; and feel that, a new journey is just began and going on. The destination is still bit far, however, I feel I am still learning about the world. I want to contribute for the societal harmony, peace and freedom. I see several severe problems i.e. the deteriorating peace in the world due conflicts and violence; environmental degradation- climate change-loss of biodiversity and unsustainable development. Additionally, I see the poverty, and the lives in Slums in the developing world. My whole, objective of the life is not to have any prestigious or easy life but devote myself in complete to empower people who could contribute to protect the environment and contribute for the social wellbeing of South and North. I have acquired knowledge, expertise and experience, which I want to share with the young and old, or anyone who thrive for knowledge and want to use knowledge to build new world of social and environmental harmony. Philosophically, I take these problems as black flies:

\section{Black flies are following us,}

From all directions, with accelerate speed,

Listen, see and feel,

Black flies are following us.

The thrust is unbelievable in them,

The desire is immense in them,

They have a power of devil,

They have a power of magic,

They are everywhere,

Beware black flies are following us.

They have a song which makes us crazy

They have a power which makes us lazy,

They sing lovely song,

They hug and kiss long

Beware friend beware,

Take out the weapon of trust, peace and awareness,

And get ready to fight with black flies,

They are everywhere as sky.

See feel and realize friend,

We have to make our path clear and pure,

We can do that it is sure,

Clear as wild rose in morning dune

Virgin as unclimbed higher mountain.

We need to know the fertility, utility and unity

As old tree sees the world with maturity,

Beware friend beware

Black flies are following us. 
Ups and down remains same

Slope and steep remains same

Travelers should have strength

Which everyone deserve by birth.

Get ready my friend get ready

Black flies are following us,

They are measuring $u s$,

\section{Examining us.}

Beware friend beware,

Black flies are following us.

Moreover, the mode if problems in the developing world and developed world seems different; however, they are omnipresent. To resolve them, both north and south needs to join hands.

I would like to assure, that these are the basis, which led me to making this the focus of my academic studies and in my long-term career. Basically, the as I said, I was, and still I am, aware of the importance of environment for human existence. I am convinced that, if I say, but not act, it does not make any sense. As a matter of fact, my motto is to continue on this work until my last breath. My request to readers, is to learn to love themselves first and think, how, we are loved by nature. If, we feel we are loved by nature (if not loved and nurtured- we were not exist), we have to love and contribute whatever we can, not for nature shake but shake of ourselves.

As a scholar of, and an advocate for, social justice, I search continuously for the links between my scholarship and the local, national, and global realities we face and with which we live. I try to bring those connections, those links between theory and real-world events with each and every day.

I go so far as to label this approach "EDUCARE"- a way to nurture constructive dialogue that cultivates the creation and recognition of a collective knowledge base even among people who may not always see eye to eye. To my mind, this is an absolutely essential aspect of living in a rapidly populating world, fraught with the dangers of viewing people who think differently as competitors or, worse, enemies. I see this approach arising naturally out of my academic interests and professional experience, which center on the intersection of identity with local, national, and global social, cultural, political, economic, and environmental change.

I strive to achieve these aims first by shaping my curriculum to enable scholarships to relate theoretical currents to their lives, for example, by having them integrate eco-friendly practices into their daily routines, such as recycling and using low-carbon transportation options. The foundation of my work is the disproportionate impact that global environmental changes are having on communities and nations that are the most vulnerable on the planet-vulnerability that has been decades, if not centuries, in the making. This vulnerability is owed to the marginalization of, if not institutionalized of, discrimination against the resident populations. I have gained field experience in Asia, Africa, the U.S., Canada, Western Europe, Australia, and the Middle East.

At personal level, I want to devote myself to find the way to resolve these problems individually and as a group. Every problem has a solution. However, the problems of the contemporary world have very long roots; history and connections. We need to resolve these problems as they have emerged. In reality, through the research, conferences, experiences and the ground truth, we know some cause of the problems. However, more rigorous research is needed to find the root of anthropogenic hampers in nature. It is also necessary to resolve the humanitarian crisis, and the way to minimize the gaps between north and south. These long-rooted problems cannot be resolved overnights. We need to develop a global strategy, which can be implemented within given time. There have been many international commitments to resolve the global crisis on environment, health and food crisis. However, the implementation part depends on the leadership of individual countries. The individual countries are not being able to overcome from the neighborhood blame culture (the problem created by south, they should solve, or by north they should pay for that etc.). In addition to that, at the global level there is no specific program for the citizen empowerment. Until or unless, citizens do not have any stake in resolving the crisis, we cannot imagine to implement any program at the ground level, where actual problem is situated. There is a strong need of long term commitments, devotions, and actual work at the ground level. The fact is "world always dominated by the noble and kind-hearted people". I am optimistic, problems are everywhere, individual to community, nations and at the globe; however, they can be solved, with collective efforts.

At the personal level, as I have experienced, I am very hopeful that doors will be opened, I am just waiting for another miraculous knock (as happened, at my primary to doctoral level study), which will provide a secure work and research platform, and I will not have to shift the babies (emerging thoughts) once place to another as wild cats do. I have still passion, perseverance, hope and energy as I had in my school years. I am energizing for the next move, waiting to connect with suitable platforms (university, research institutions, international organizations or any other agencies, who are thriving to make the positive impact on social and natural environment) to begin the new journey collectively.

Q: We know that South Asia has been an area of special expertise in your studies. In your opinion, what are the most serious environmental issues facing India, Pakistan, Nepal, and Bangladesh today?

Yes, originally, my area of practical work and research was focused Asia, particularly in Nepal, where I born, extended to India where I got my intermediates and bachelor degrees. And, I was attracted and motivated explore more about Bangladesh and Pakistan who belong to similar social and environmental problems. However, I am equally concerned and working to other geographical locations like east Africa, Australia, Japan, middle east, Europe, Eurasia, post-Soviet countries and north America etc. As I noted above, one way or other, the entire world has similar problems, in terms of environmental issues, therefore, in my research, always I see the global scenario and narrow down to specific geo-locations.

Primarily, environmental issues emerged due to anthropogenic disturbances on nature and natural resources or we can state that it is human impact on the living environment (ecosystems). Worldwide, there are many environmental problems, few of them can be listed in Table 2.
Submit your Article | www.ologyjournals.com/submit-article

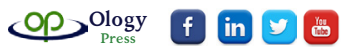

Citation: Bhandari MP. "BashudaivaKutumbakkam"-The entire world is our home and all living beings are our relatives. Why we need to worry about climate change, with reference to pollution problems in the major cities of India, Nepal, Bangladesh and Pakistan. Adv Agr Environ Sci. (2019);2(I): 8-35. DOI: 10.3088I/aaeoa.000I9 
Table 2 Current environmental concerns. ${ }^{21}$

\begin{tabular}{lll}
\hline Contamination of Drinking Water & Water Pollution & Air Pollution \\
\hline $\begin{array}{l}\text { Wildlife Conservation and Species } \\
\text { Biologinction }\end{array}$ & Loss of Tropical Rainforests & Climate Change/Global Warming \\
$\begin{array}{l}\text { Dams and their impact on the } \\
\text { environment }\end{array}$ & Carbon footprint & Consumerism \\
$\begin{array}{l}\text { Fishing and its effect on marine } \\
\text { ecosystems }\end{array}$ & Food safety & Energy conservation \\
Intensive farming & Land degradation & Genetic engineering \\
Deforestation & Mining & Land use \\
Natural disaster & Nuclear issues & Nanotechnology and future effects of Nano \\
Overpopulation & Resource depletion & pollution/nanotoxicology \\
Sustainable communities & Toxins & Other pollution issues \\
\hline
\end{tabular}

Basically, these all and many more are the serious environmental issues in India, Pakistan, Nepal, and Bangladesh as well as to South Asia. However, Pollution; Climate Change; Global Warming; Deforestation and Overpopulation impacts are commonly known environmental issues in the region. Table 3 shows a summary of the data.

Table 3 A brief comparative account of four countries (territory, demographics, economics, and health profiles). ${ }^{22-25}$

\begin{tabular}{|c|c|c|c|c|c|}
\hline Category & Indicators & IND & PAK & BGD & NPL \\
\hline \multirow{8}{*}{ Population } & Territory (land surface in $000 \mathrm{Sq} . \mathrm{Km}$.) & 3287 & 796 & 144 & 147 \\
\hline & Population density (per Sq.km.) 2008 & 361 & 210 & 1120 & 195 \\
\hline & 2016 & 445 & 251 & 1252 & 202 \\
\hline & Increased in 8 years & 84 & 41 & 132 & 7 \\
\hline & Total (million) 2016 & $\mathrm{I}, 324.2$ & 193.2 & 163 & 29 \\
\hline & Rural (\% of total) & 71 & 64 & 73 & 83 \\
\hline & Over 65 years (\% of total) & 5 & 4 & 4 & 4 \\
\hline & Young & 50 & 63 & 50 & 63 \\
\hline \multirow{7}{*}{ Economy } & Old & 8 & 7 & 6 & 7 \\
\hline & GNI/capita (US\$) & $\mathrm{I}, 220$ & 1,000 & 580 & 440 \\
\hline & PPP GNI/capita (US\$) & 3,280 & 2,680 & $\mathrm{I}, 550$ & 1,180 \\
\hline & Annual growth GDP (\%) & 7.3 & 2 & 6.2 & 5.3 \\
\hline & $\%$ male 15 years and older & 81 & 85 & 84 & 76 \\
\hline & $\%$ female 15 years and older & 33 & 21 & 58 & 63 \\
\hline & Extreme Poverty (\% <US\$I.25 PPP) & 41.6 & 22.6 & 49.6 & 55.1 \\
\hline \multirow{3}{*}{ Health Indicators ${ }^{a}$} & Mortality rate, infant (per I,000 live births) & 52 & 73 & 43 & 41 \\
\hline & Maternal mortality ratio (per 100,000 live births) & 450 & 320 & 570 & 830 \\
\hline & Crude death rate (per I,000 population) & 7 & 7 & 7 & 6 \\
\hline \multirow{3}{*}{ Health Services } & Life expectancy (years) & 64 & 67 & 66 & 67 \\
\hline & Hospital beds (per 10,000 populations) & 7 & 10 & 3 & 2 \\
\hline & Physicians (Density per 10000 population) & 6 & 8 & 3 & 2 \\
\hline \multirow{3}{*}{ Health Financing } & Total expenditure on health (\% of GDP) & 4 & 2.9 & 3.5 & 4.9 \\
\hline & General government expenditure on health ( $\%$ of total) & 28 & 29.7 & 35.7 & 39 \\
\hline & Per capita total expenditure on health (US\$) & 43 & 24 & 17 & 20 \\
\hline
\end{tabular}

BGD = Bangladesh, IND=India, NPL=Nepal and PAK=Pakistan.

${ }^{a}$ per 10,000 individuals

Note: Data are for 2008 except for health services (2009), extreme poverty (2002-2005), maternal mortality ratio (modeled estimates, 2005), hospital beds (2000-2008), and physicians (2000-2007). 
The impacts of these issues impact depend on the geo-locations. For example, degree of pollution can be reduced in short period of time if emission reduction policy implemented and used the modern tools to reduce pollutants but global warming -which is causing sea level rise, habitat change, disasters etc. are very severe also difficult issues to solve. Global warming and climate change are interconnected issues and there is no quick fix and short-term solutions. The impacts of such issues emerged due to long anthropogenic interventions in the natural environment, and as they are cumulative impacts, to overcome from such issues also need collective and continuous efforts from local to international levels.

The impacts depend on their geographical locations, size, economic status, and coping mechanism to deal with the crisis. For example, Bangladesh and Nepal belongs same region and have almost same geographical size, however, the degree and the modality of problems are different, but interconnected. For example, one of the impacts of global warming is having "long lasting effects which can result in melting of glaciers, climate change, droughts, diseases and increase in hurricanes frequency." ${ }^{26}$ Here, if we examine the scenario, Nepal's glaciers melting helping sea level rise and Bangladesh, which is belong to low land has direct effects of sea level rise. As such this interconnectedness applies to entire planet. This also brings us to the point of interdependency of chain of ecosystems. As social scientist I also see interconnections of social system and our behavior with our environment as well as to the society. As known notion, industrialization process occurred during 1760-1840 in western industrialized world and continues to date and will continue to future (modality might be different but objectives remains the same (efficiency and production). We need to think who are the victims? We know, what is the answer; however, it is too late to blame to the past or even to present. It's time to consider the fact, the entire planet is victim and only collectively we can minimize the severity of the environmental problems.

The following is an excerpt from: The impact of pollution on planetary health: emergence of an underappreciated risk factor by Philip J. Landrigan, and Richard Fuller ${ }^{27}$

Pollution is a massive, overlooked cause of disease, death and environmental degradation. ......Pollution was responsible in 2015 for 9 million premature deaths - three times as many deaths as caused by AIDS, tuberculosis and malaria combined. 92\% of PRD occurs in low and middle-income countries (LMICs), and in the hardest hit countries, PRD is responsible for more than 1 death in 4 . Household air and water pollution, the traditional forms of pollution, are decreasing, and deaths from pneumonia and diarrhea are down. But ambient air, chemical and soil pollution are all on the rise, and non-communicable diseases (NCD) caused by these forms of pollution are increasing. Pollution and climate change are closely linked; both arise from the same sources, and both can be controlled by similar solutions. PRD causes great economic losses. These include productivity losses that reduce gross domestic product in LMICs by up to $2 \%$ per year as well as health care costs that account for $1.7 \%$ of health care spending in high-income countries and up to 7\% in LMICs. Welfare losses due to pollution are estimated to amount to $\$ 4.6$ trillion per year, $6.2 \%$ of global economic output.

Going back to four Asian countries mostly, I consider ten environmental issues of Environmental Performance Measurement Index developed by Yale University's Center for Environmental
Law and Policy, and Columbia University's Center for International Earth Science Information Network in collaboration with the World Economic Forum and the Joint Research Centre of the European Commission. ${ }^{28}$ In the index they use ten categories (1) environmental burden of disease; (2) water resources for human health; (3) air quality for human health; (4) air quality for ecosystems; (5) water resources for ecosystems; (6) biodiversity and habitat; (7) forestry; (8) fisheries; (9) agriculture; and (10) climate change, which I consider major environmental issues of global importance. However, I would like to restate, that Pollution; Climate Change; Global Warming; Deforestation and Overpopulation are the severe environmental issues of South Asia. The degree of problems are different in each countries. For example, Nepal's major issues are, Deforestation (need to fulfill the demand growing population); Soil erosion (due to elevation, landslides are common); Pollution (crowding cities-air, water, soil pollutions are common); Climate change impact on glaciers and melt. Bangladesh- except glacier all applies; Pakistan: all applies and for India all above applies in full phase. However, degrees can be different.

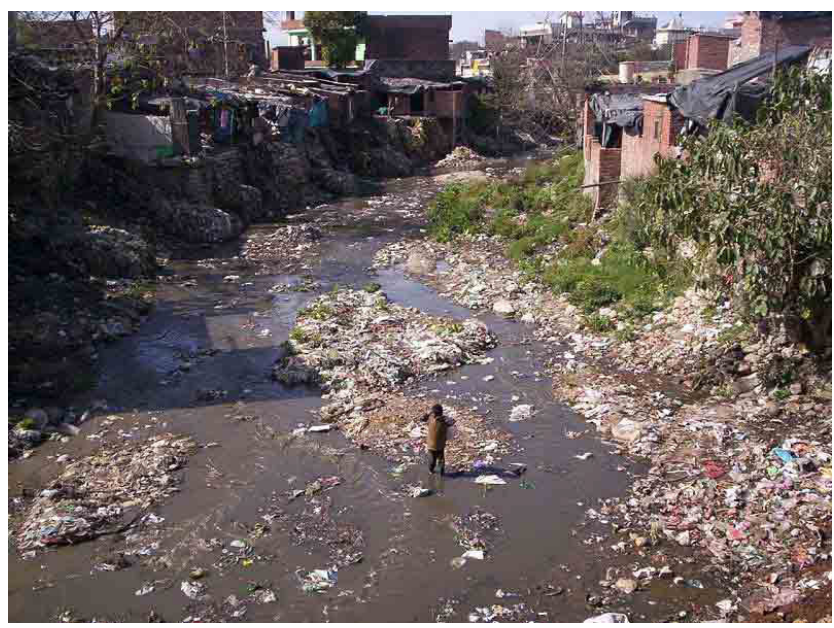

Sewage and waste management problem. ${ }^{29}$

Q: We would like to briefly discuss Bangladesh for a moment. All countries in Asia and throughout the world are facing the effects of climate change and will be affected in various ways. However, Bangladesh, with approximately $46 \%$ of its population living in areas a mere $\mathbf{1 0}$ meters above sea level, would seem to be one of the most vulnerable in Asia. Can you briefly discuss how climate change will affect the lives of these $\mathbf{7 5}$ million people, what steps the govt. is taking to mitigate these effects, and whether you think Bangladesh is doing enough? Can the government do enough?

Yes, you are absolutely right. We have been witnessing the effects of climate change, even in our day to day lives. As EDF notes "A warming Earth disturbs weather, people, animals and much more". There are ample of evidences that more heat alters ice, weather and oceans (The cryosphere - the frozen water on Earth - is melting; Weather is getting more extreme; The oceans are getting hotter, expanding and becoming more acidic); Human life and prosperity suffering [(Climate change is a major threat to agriculture: Farms are more likely to face attacks from weeds, diseases and pests, which reduce yield; Warmer, polluted air affects our health; Infrastructure and transportation are at risk]; natural habitats become hostile-(The ice Arctic animals need is vanishing; Coral and shellfish are suffering; Forests are more prone to deadly infestations). ${ }^{30} \mathrm{I}$ am sure, we all
Submit your Article | www.ologyjournals.com/submit-article Q
Citation: Bhandari MP. "BashudaivaKutumbakkam"-The entire world is our home and all living beings are our relatives. Why we need to worry about climate change, with reference to pollution problems in the major cities of India, Nepal, Bangladesh and Pakistan. Adv Agr Environ Sci. (2019);2(I): 8-35. DOI: 10.3088I/aaeoa.000I9 
have seen many environmental changes one way or another. We have been witnessing very frequent extreme disastrous even within decades. Such events are more severe in the climate prone country like Bangladesh.

The climatic hazards have always leaded the human casualties, poverty and extreme economic damage in Bangladesh. In 1970 about 500,000 people were killed due to cyclone alone in Bangladesh. For example, from 1971 to 2001, about 505,378 people were killed 147, 5994 were insured and 3625, 1500 people became homeless. During these 30 years about 33 million people of Bangladesh were affected directly from the climatic hazards, which damaged more than US\$10 billion worth of property (Government of Bangladesh 2001:113-117). ${ }^{31}$

I think, most worrisome problem of Bangladesh is impact of sea level rise (which is already visible), over population (most densely populated country), and people dependency on agriculture (which is also very fragile). The following brief notes from Rezaul Karim provides a nice snap of the major problems:

\section{Climate Change \& its Impacts on Bangladesh ${ }^{32}$}

Bangladesh is one of the largest deltas in the world which is highly vulnerable to Natural Disasters because of its Geographical location, Flat and low-lying landscape, Population density, Poverty, Illiteracy, Lack of Institutional setup etc. In other words, the Physical, Social as well as Economic conditions of Bangladesh are very typical to any of the most vulnerable countries to Natural Disasters in the world. The total land area is $147,570 \mathrm{sq}$. km. consists mostly of Floodplains (almost $80 \%$ ) leaving major part of the country (with the exception of the north-western highlands) prone to flooding during the rainy season. Moreover, the adverse effects of Climate Change - especially High Temperature, Sea-level Rise, Cyclones and Storm Surges, Salinity Intrusion, Heavy Monsoon Downpours etc. has aggravated the overall Economic Development scenario of the country to a great extent. Bangladesh experiences different types of Natural Disasters almost every year because of the Global Warming as well as Climate Change impacts, these are:

- Floods / Flash Floods (Almost $80 \%$ of the total area of the country is prone to flooding).

- Cyclones and Storm Surges (South and South-eastern Parts of the country were hit by Tropical Cyclones during the last few years).

- Salinity Intrusion (Almost the whole Coastal Belt along the Bay of Bengal is experiencing Salinity problem).

- Extreme Temperature and Drought (North and North-western regions of the country are suffering because of the Extreme Temperature problem).

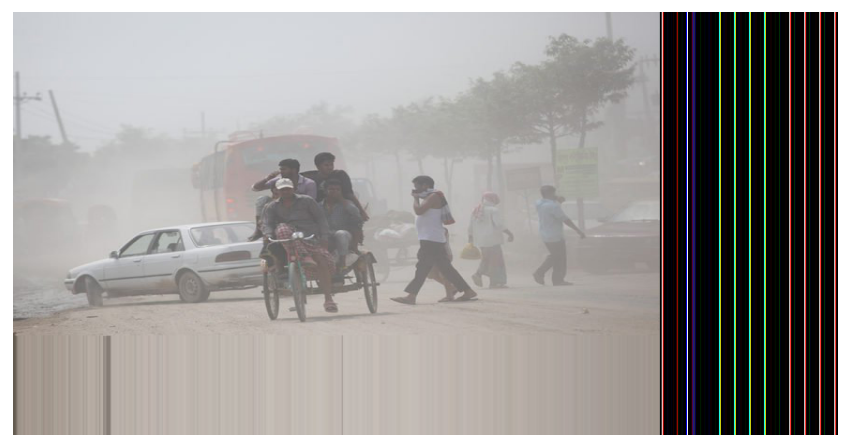

Landscape full of trash in Bangladesh ${ }^{33}$

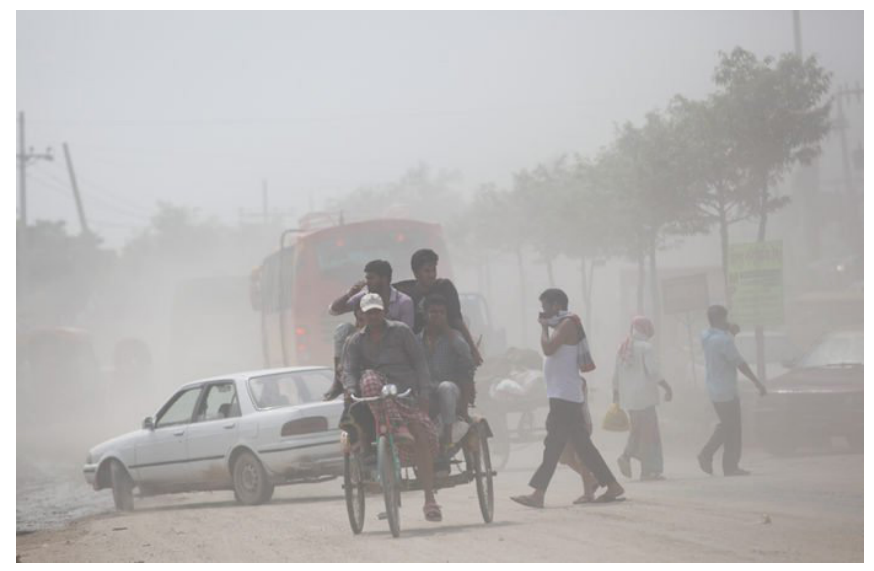

Bangladesh losing I\% of its GDP every year due to air pollution. ${ }^{34}$

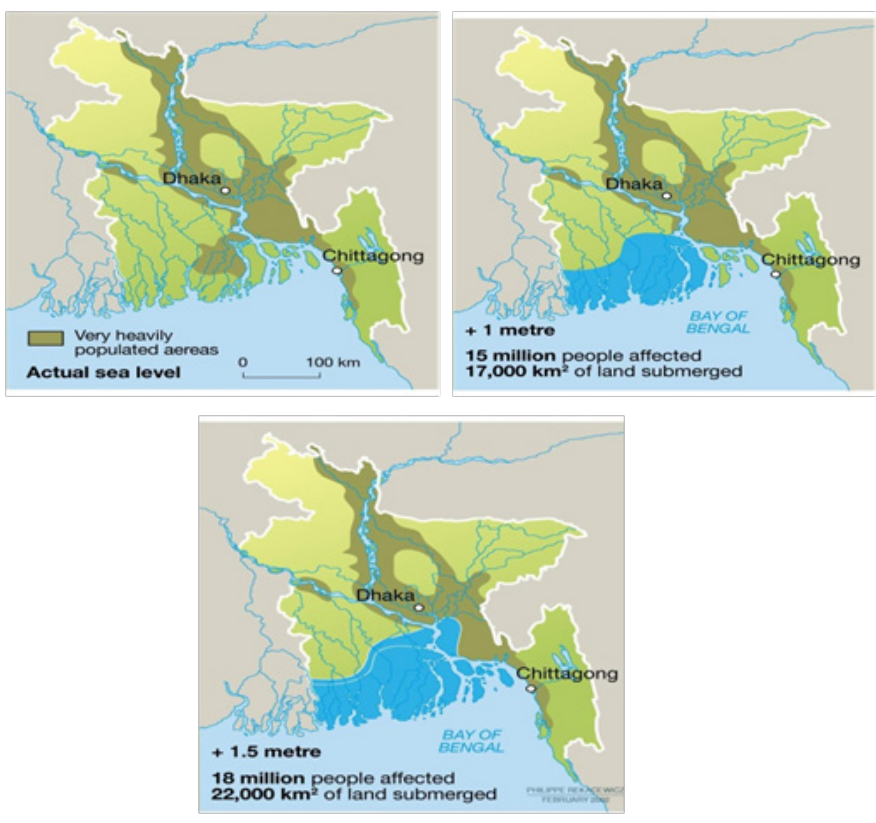

Impact of sea level rise in Bangladesh.Three maps in a time relapse resulting in 18 million people affected, $22,000 \mathrm{~km}^{2}$ of land submerged by flooding. ${ }^{35}$

Below is an excerpt from Brammer ${ }^{36}$ :

"Bangladesh's exposure to the growing hazard of sea-level rise in the 21 st century needs to be seen in the perspective of its exposure to current environmental hazards and its growing development needs. If sea-level is currently rising at $1.3 \mathrm{~mm} /$ year, that is by only $13 \mathrm{~mm}$ $(=0.5$ inch $)$ in 10 years. Even if the rate is $3 \mathrm{~mm} /$ year, that is by only $30 \mathrm{~mm}$ (=1.2 inches) in 10 years. But Bangladesh's population of 150 million is currently growing at ca 2 million a year: i.e., it could grow by 20 million in the next 10 years. That will generate much greater pressure on the country's land and water resources and its economy than will a slowly-rising sea-level. The country's agricultural land is already fully developed; in fact, considerable areas of valuable farmland are being lost to expansion of settlements and infrastructure each year."

Similarly, the IPCC in its first assessment report estimated that a 1 -meter rise in sea level could inundate 17 percent of Bangladesh ..... and that this could decrease the agricultural productivity of many delta countries that can least afford losses. ${ }^{37}$ The IPCC further noted,
Submit your Article | www.ologyjournals.com/submit-article OP Ology
Citation: Bhandari MP. "BashudaivaKutumbakkam"- The entire world is our home and all living beings are our relatives. Why we need to worry about climate change, with reference to pollution problems in the major cities of India, Nepal, Bangladesh and Pakistan. Adv Agr Environ Sci. (2019);2(I): 8-35. DOI: 10.3088I/aaeoa.000 I9 
in the case of tropical Asia that the projected climate changes ... include strengthening of monsoon circulation, increases in surface temperature, and increases in the magnitude and frequency of extreme rainfall events. ... These changes could result in major impacts on the region's ecosystems and biodiversity; hydrology and water resources; agriculture, forestry, and fisheries; mountains and coastal lands; and human settlements and human health. Similarly, in the additional remarks IPCC noted that the individual countries, regions, resources, sectors, and systems will be affected by climate change not in isolation but in interaction with one another (IPCC 1998: 403). ${ }^{38}$ Likewise, in the third assessment report (TAR) it states that the deltas will be exposed to potential inundation both due to climate change and to human-induced stresses..$^{39,40}$

The following pictures show environmental problems in Bangladesh:

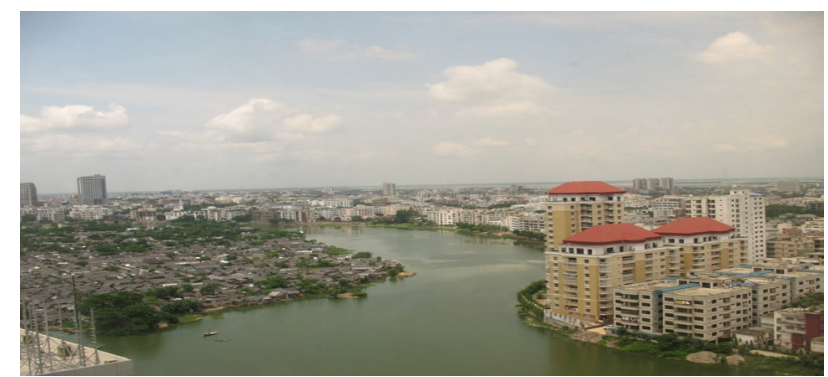

Crowded city of Dhaka. (Photo by: Medani Bhandari-during field visit)

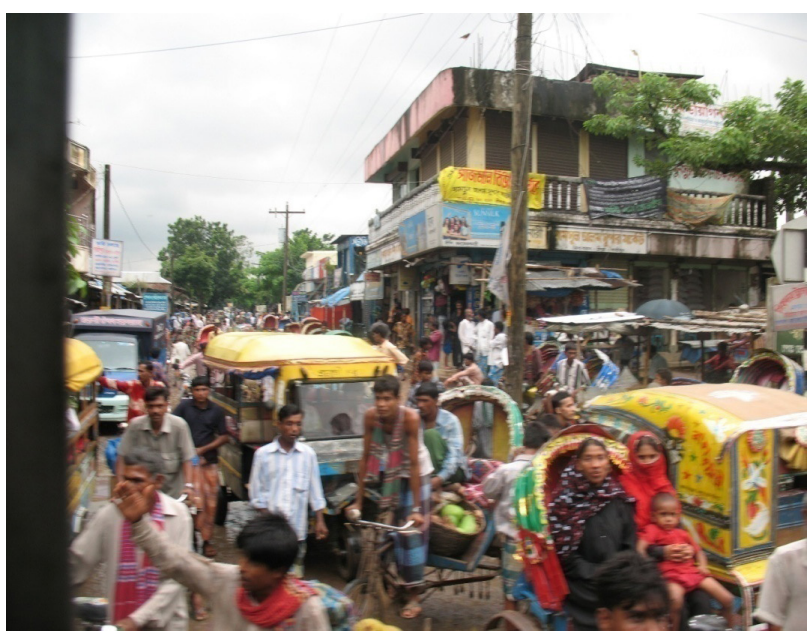

Crowded city of Dhaka. (Photo by: Medani Bhandari-during field visit)

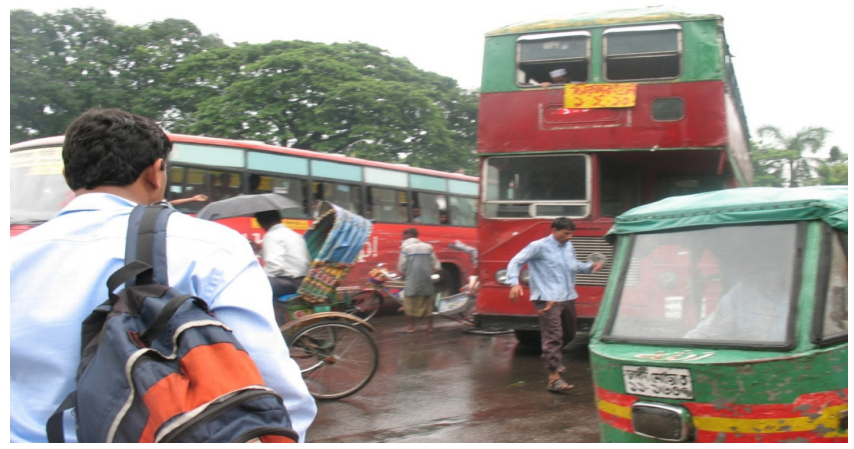

Crowded city of Dhaka. (Photo by: Medani Bhandari-during field visit)

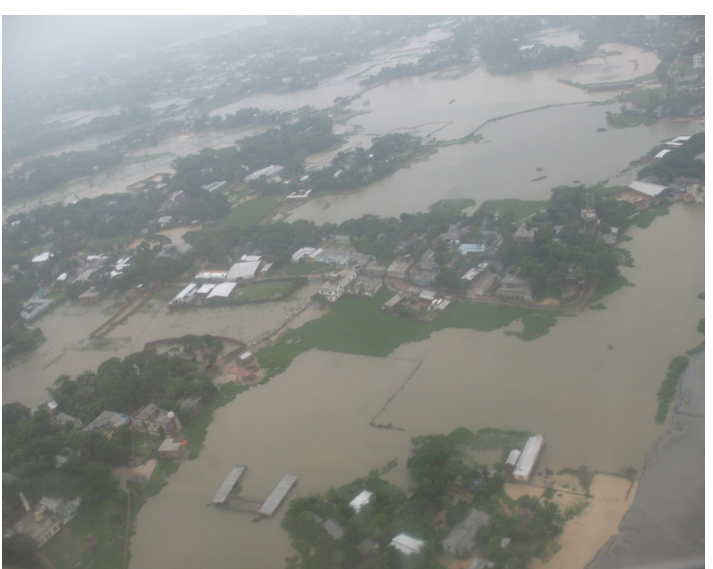

Bangladesh flood from above (Photo by: Medani Bhandari-during field visit)

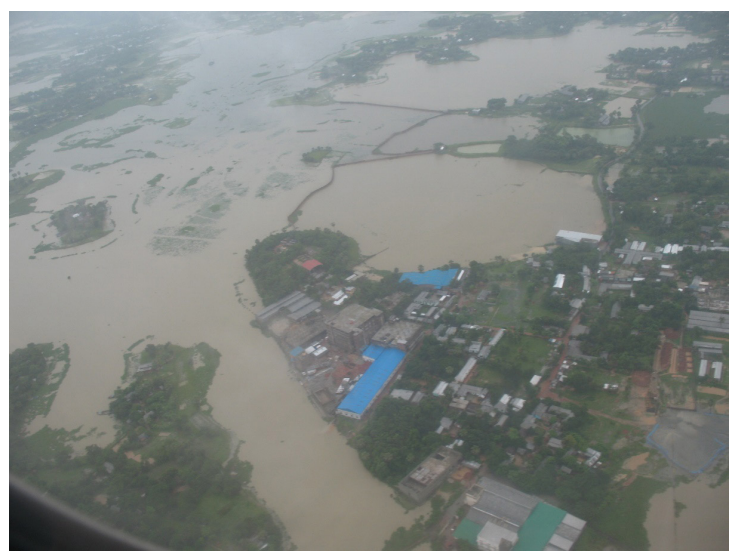

Bangladesh flood from above (Photo by: Medani Bhandari-during field visit)

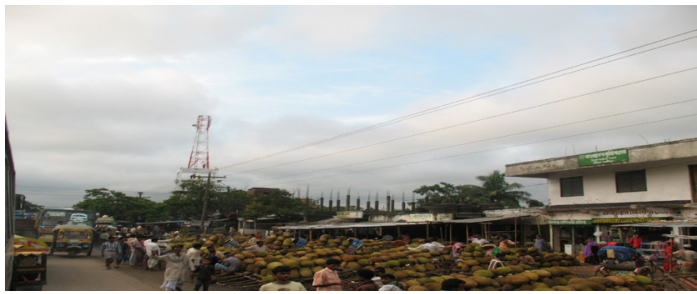

Fruit (Jackfruits) market, on the way to Maiman Singh, Bangladesh (Photo by: Medani Bhandari-during field visit)

Bangladesh's capital Dhaka has again ranked as the most polluted city in the world. ${ }^{41}$
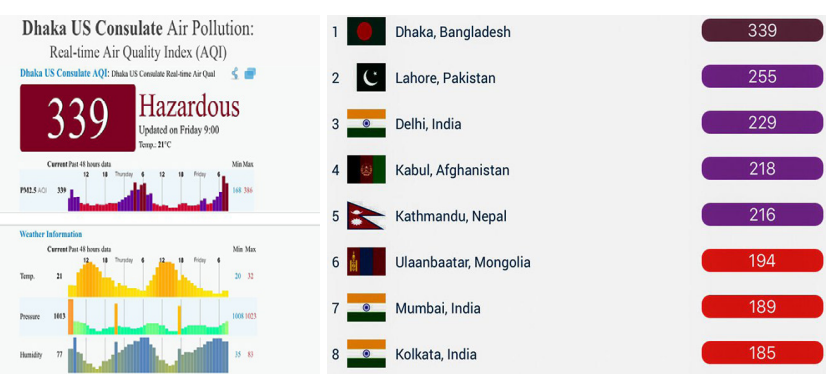

In summary, Bangladesh is having serious environmental problems, both natural and anthropogenic. Bangladeshi people are aware of overall climate change scenarios and severity of its impact in their day-to-day lives. For example, according to World Bank public
Citation: Bhandari MP. "BashudaivaKutumbakkam"-The entire world is our home and all living beings are our relatives. Why we need to worry about climate change, with reference to pollution problems in the major cities of India, Nepal, Bangladesh and Pakistan. Adv Agr Environ Sci. (20I9);2(I): 8-35. DOI: I0.3088I/aaeoa.000 I 9 
survey report of 2009, in reposes on seriousness of climate change as a problem, 85 percent of public reported as very serious problem and 14 percent reported as serious problem; similarly in response to the climate change as priority 54 percent reported as topmost priority and 34 percent reported and priority; in terms of urgency to address 67 percent reported that climate change impact is affecting now, followed by 26 percent reported that it will affect within 10 years. ${ }^{42}$

The government of Bangladesh is also very serious in addressing the climate change induced problems. For example, the Government of Bangladesh report to its citizens and the global community disseminated on September 2007, states that the rapid global warming has caused fundamental changes to our (Bangladesh) climate. No country and people know this better than Bangladesh, where millions of people are already suffering. Sudden, severe and catastrophic floods have intensified and taking place more frequently owing to increased rainfall in the monsoon.......Bangladesh is recognized worldwide as one of the country's most vulnerable to the impacts of global warming and climate change.

\section{What the government is doing:}

The phrase "No country and people know this better than Bangladesh" used by the government actually spell out the truth which they have been experiencing the risk, insecurity, conflicts and the severity of climate change impact, for which they say the innocent victims of global warming.

The major step began from the approval of the UNFCCC on June 09, 1992 which was ratified on April 15, 1994. To fulfill the commitments to the UNFCC and other international obligations the government of Bangladesh also prepared several legal and policy instruments.

The government of Bangladesh has taken major step to cope with the national environmental crisis and shown its strong commitment by preparing and submitting the National Adaptation Plan of Action (NAPA) plan to UNFCC in $2005 .{ }^{43}$ The NAPA is the policy guidance which outlines the major program and plan in addressing the climate change issues in Bangladesh. This action plan was prepared as a response to the decision of the Seventh Session of the Conference of the Parties (COP7) of the United Nations Framework Convention on Climate Change (UNFCCC) With the consideration of adverse effects of climate change including variability and extreme events based on existing coping mechanisms and practices, the NAPA (2005) recommended adaptation strategies.

However, the environmental risk factors are not only associated with the climate change but also associated with the deep-rooted poverty, population growth, insecurity and also the instable government and its ineffectual administrative system. So far, there are no any visible achievements, however, generally, the Government seems convinced to materialize the aim "to eradicate poverty and achieve economic and social well-being for its entire people, through a pro-poor, climate resilient and low-carbon development by adaptation to climate change, mitigation, technology transfer and adequate and timely flow of funds for investment, within a framework of food, energy, water and livelihoods security." ${ }^{44}$

Bangladesh is actively participating and with the international Treaty Obligations related to environment conservation including climate change and its initiation for the forests and environment management since 1972 clearly indicates that the country's seriousness to address the environment issue internationally and domestically. In the
Bangladesh environmental conservation history of global relations another significant milestone step was signing of the Convention on Biological Diversity, at the Earth Summit in 1992, and preparation of policy guidelines to manage the biodiversity in the country. In the Bangladesh environmental conservation history, the international organizations have been playing the major role those includes the UN agencies, multilateral donor agencies, development banks, embassies of developed world, conservation international organizations and the NGOs and general concern citizens, in the specific areas of their expertise.

On the basis of available literature, my interaction with locals, NGOs, INGOs and government official, I conclude that, most of the concerned stakeholders (general public, NGOs communities, government et.) are aware of the adverse impact of environmental change due to global warming and climate change. Particularly, the residents of coastal area are also worried, who witnessing increasing hazardous weather pattern. I find them, brave, courageous and optimistic. They have developed own way of survival. The international agencies, NGOs, national and local governments are also working hard to save this vulnerable areas' lives, through early warning systems (cell phones, radio, TV, information stations), and by supplying the essential tools and equipment. However, in comparison to the severity and intensity problems, the available coping mechanism are too minimal. Bangladesh needs global help and resources even to minimal minimization of this problem.

Q: Many of our readers focus on the larger, more industrialized, wealthier, and probably more polluted countries: China, Vietnam, Malaysia, Indonesia, Pakistan, and India. Nepal is somewhat forgotten. Can you tell us what major environmental issues are facing Nepal?

I do not think Nepal is less focused or forgotten country in terms of climate change. Even in terms of pollution, Nepal's capital Kathmandu is considered among the list of most polluted cities in the world. Below shows an excerpt from The Himalayan Times, published: July 05, 2017 $7^{45}$ :

\section{Nepal's Kathmandu ranks 5th in Pollution Index 2017}

"KATHMANDU: Nepal's capital city Kathmandu has ranked 5th in Pollution Index 2017 mid-year as published by the Numbeo.com recently. ....Kathmandu slumps two spots down to 5th with 96.57 pollution index. Numbeo said it included relevant data from World Health Organization and other institutions for the ranking. The cities were listed on the basis of air pollution and then the water pollution/ accessibility followed by other pollution types.

According to the Department of Environment of Nepal, the particulate matter (PM 2.5) of Ratnapark is $107 \mu \mathrm{g} / \mathrm{m}^{3}$ marking Kathmandu as one of the unhealthy cities to live in.

PM 2.5 indicates the matter present in the air that are 2.5 microns or below. These particles include dust, coal, particles exited from power plants and home heating, car exhaust and pollen plants among others. Kathmandu's downfall was heralded due to the snailpaced road expansion projects in the Kathmandu Valley and delay in the underground installation of Melamchi Drinking Water pipes in the city. The government's failure to replace the old and outdated vehicles plying on the roads of the city have also added air pollution
Submit your Article | www.ologyjournals.com/submit-article

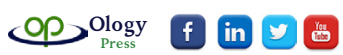

Citation: Bhandari MP. "BashudaivaKutumbakkam"- The entire world is our home and all living beings are our relatives. Why we need to worry about climate change, with reference to pollution problems in the major cities of India, Nepal, Bangladesh and Pakistan. Adv Agr Environ Sci. (2019);2(I): 8-35. DOI: 10.3088I/aaeoa.000 I9 


\section{in Kathmandu.}

Similarly, in recent years, dust pollution has been another big threat and subject of major concern for the public health. Below shows an excerpt from The Himalayan Times, published: February 17, $2017^{46}$ :

\section{Kathmandu Valley: Dust bowl of pollution, by Surendra Bahadur Sijapati}

Pollution is more vicious than modern-day terrorism. Leave it unchecked and it will strangulate every living thing on this planet. So all who love or live in the Kathmandu Valley must work hand in hand to deal with and eradicate pollution.................Between the words, however, it literally hid the day to day sufferings of the inhabitants of Kathmandu Valley blended in blinding and suffocating dust, excruciating noise and nasty smell. The so-called capital city of Nepal and a national melting pot is rapidly turning into a "dust bowl" of pollution, unhindered.

It is easy to tag Kathmandu as "Dustmandu" or "Maskmandu" which merely illustrates the tip of the iceberg. But underneath, a huge white core is hidden and we must responsively act before it is too late. Just imagine, one little spark of a pandemic can cause a huge loss.

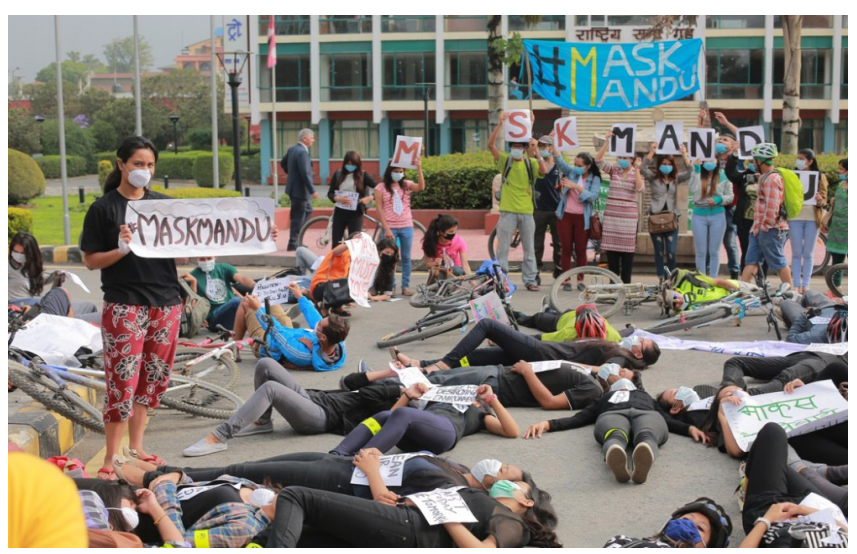

World Environment Day: Campaigners lay dead demanding right to clean air. ${ }^{47}$

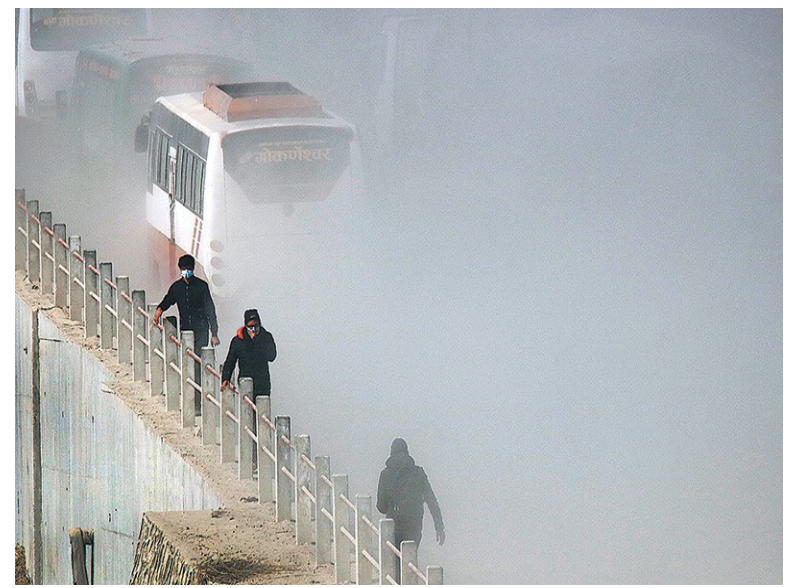

Nepal's air quality is worst in the world: EPI report; Post Report. ${ }^{48}$

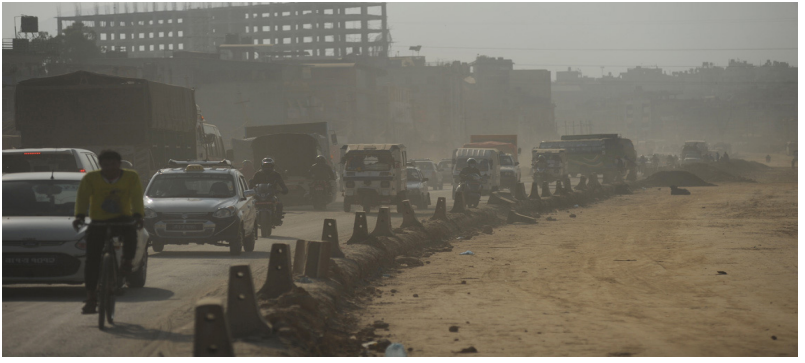

While the government has failed to tackle increasing air pollution, Nepal stands the fifth worst country in the world in curbing air pollution, according to Environmental Performance Index (EPI)'s latest rankings. Nepal ranked I76 out of 180 countries. ${ }^{49}$

The above images and media's named the synonyms DUSTMANDU or MASKMANDU for Kathmandu actually depicts the reality of pollution in Kathmandu. One aspect, I would like to restate that, people in South Asia are very active and concerned on the issues of public concern, whether, it is the case of Dhaka, Delhi, Karachi, or Kathmandu.

Going back to the question on major environmental problems in Nepal, they are similar to Bangladesh (except direct impact of sea level rise and coastal related problems). However, Nepal's geographical situation is different than any country in the world, due to its altitudinal variations, which can be divided as a) Low land 60 to 900 meters from sea level; b) Midland 900 to 2500 meter from the sea level; c) Highland 2500 to 2750 meter from the sea level and d) Trans-Himalayan 2750 to 8848 meter from the sea level.

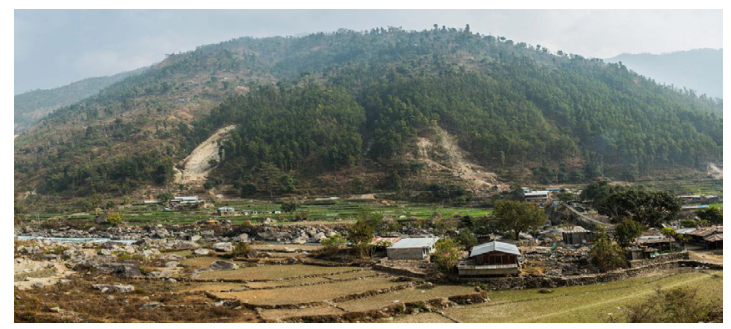

After devastating earthquake, Nepal aims to reduce the risk of disaster through green rebuilding. ${ }^{50}$

The extreme altitudinal gradient of Nepal results the occurrence of 10 bio-climatic zones from tropical to naval within a horizontal span of less than $180 \mathrm{~km}$ virtually making Nepal a treasure house of biological and cultural diversity. A total of 118 ecosystems, 75 vegetation and 35 forest types have been identified. Nepal comprises seven ecological zones which occur in the following order from south to north: (a) Terai, (b) Siwalik zone, (c) Mahabharat Lekh, (d) Midlands, (e) Himalaya, (f) Inner Himalaya, and (g) Tibetan marginal mountains. The diversity, threats, strategies and action plans of Nepal have been discussed under six broad categories viz. forests, rangelands, protected areas, agroecosystems, wetlands, and mountain ecosystem (Lillesø; Shrestha; Dhakal; Nayaju and Shrestha 2005; Dahal 2004; Bhattarai 2005). The impact of changing environment varies; we still do not know the degree of impact and severity different ecosystems. In general, the identified (those are similar to Bangladesh, India, Pakistan) major environmental problems of Nepal can be summarized as: (1) Degradation of air quality, (2) Degradation of drinking water, (3) Degradation of natural resources, (4) Lack of solid waste management, (5) Degradation of surface water quality, (6) Diminishing of water resources, (7) Release of toxic pollutants, (8) Loss of biodiversity, (9) Impacts of climate change, and (10) Improper land use. ${ }^{51}$
Citation: Bhandari MP. "BashudaivaKutumbakkam"-The entire world is our home and all living beings are our relatives. Why we need to worry about climate change, with reference to pollution problems in the major cities of India, Nepal, Bangladesh and Pakistan. Adv Agr Environ Sci. (2019);2(I): 8-35. DOI: 10.3088I/aaeoa.000I9 


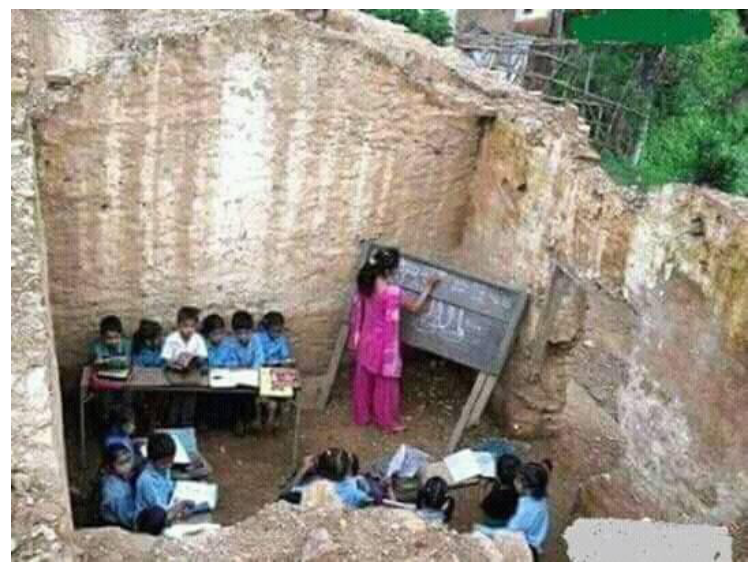

This picture tells another story of Nepal. ${ }^{52}$

Q: Climate change tends to hit low-lying areas, as well as naturally more arid areas, more severely. Is climate change a threat to Nepal, and if so, how?

The impact of climate change has been noticed globally, however, it is more visible in the climate sensitive areas such as in Himalayas or the lowland and coastal islands including countries like Nepal (high Himalaya), Bangladesh other countries located in climate prone areas. In this context Nepal belongs to the vulnerable to climate change due to its extreme elevation variations.

Its elevation increases from south to north and is accompanied by decreasing temperatures. It is the home of the 8 of the 10 highest mountain peaks of the world, including Mount Everest (at $8848 \mathrm{~m}$ ), with the lowest area of about 60 (Kechanakalan, Jhapa) meter from sea level. Nepal contains a climatic variation of tropical to arctic within the distance of about 200 kilometers south to north containing lower land Terai plain, Siwalik Hills, Middle Mountains, and High Mountains. ${ }^{53-55}$

Several international institutions, bilateral and multilateral agencies and independent authors including the government of Nepal have highlighted the impact of the climate change in Nepal; however, still it has limited information regarding the impacts of climate change in economic growth, development, resource conservation and basic livelihood. ${ }^{54-61}$ For example, USAID in its Country Assistance Strategy Nepal for 2009-2013, highlights that Nepal is extremely vulnerable to natural disasters due to its elevation. The strategy states that Nepal has an extraordinarily high vulnerability to natural disasters - including major floods, landslides, drought and earthquakes due to its geographic location, low levels of development, minimal infrastructure and institutional capacity, and dependence on rainfed agriculture. Severe rural poverty causes populations to inhabit marginal lands in areas at high risk for natural disasters, which is then aggravated through unsustainable practices (deforestation, over-farming or over-grazing) ... There are several critical gaps and impediments to addressing Nepal's vulnerability to disasters. Many of the most vulnerable populations are also the most physically remote, impoverished, and the least-educated.$^{60}$

"Nepal's diverse geography makes it vulnerable to various climatic impacts, including extreme temperatures, erratic rainfall, drought, floods, melting snow and glacier retreat. The mountain areas are also vulnerable to glacial lake outburst floods (GLOFs) from melting glaciers, a risk. " 62

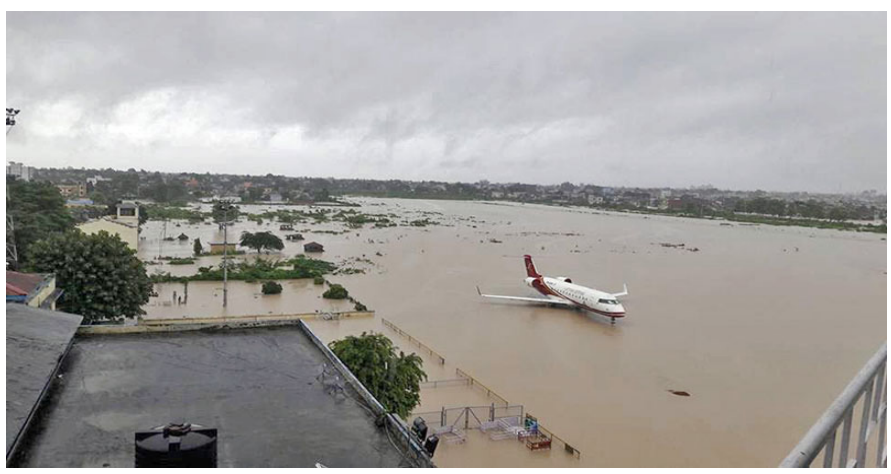

A lone plane is seen at the Biratnagar Airport inundated by flash flood triggered by incessant rainfall in the area, as captured on Tuesday, August 15, 2017.63
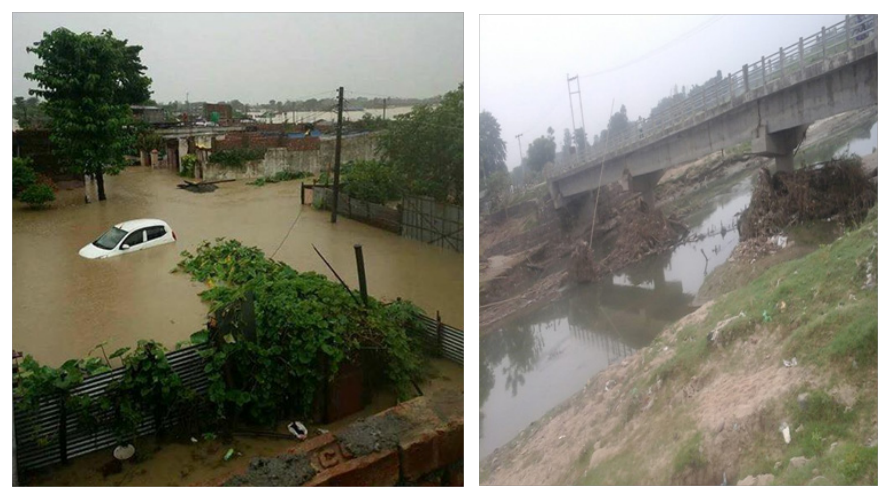

Unexpected rainfall and flood in Biratnagar-Nepal-photo credit NilamNiraulaFacebook

Below is an excerpt from BBC Media: Nepal-How the people of Nepal live with climate change and what communication can do. ${ }^{62}$

Nepalis believe that temperatures have risen, rainfall has become less predictable and floods and droughts have increased during the last 10 years. People also feel the environment has changed and nearly nine in ten say that insects and pests have increased.

They feel the impact of these changes in climate now - over half say that agricultural production is decreasing and the majority think that these changes are having an impact on their health. The majority of people (66\%) feel very worried about the impact these changes will have on their lives in the future - more than in any of the other six Climate Asia countries. This worry comes both from their personal experiences and from media coverage.

People are taking action and responding to these changes - one in five have made changes to their livelihoods, including changing job, supplementing their income or migrating. People are also making smaller changes; for instance farmers are rotating crops and growing different crops. However, people want to take more action. In fact, among all the Climate Asia countries, Nepalis are the most willing to make more changes to adapt. The majority strongly want to make changes to improve agricultural production, prepare more for floods and droughts and cope better with water shortages. Most people are struggling to take as much action as they would like for a number of reasons. They feel they need more money, government backing and information on how to respond. Others, such as some housewives from the Eastern and Central Terai, feel isolated within their communities
Submit your Article | www.ologyjournals.com/submit-article

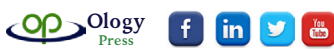

Citation: Bhandari MP. "BashudaivaKutumbakkam"- The entire world is our home and all living beings are our relatives. Why we need to worry about climate change, with reference to pollution problems in the major cities of India, Nepal, Bangladesh and Pakistan. Adv Agr Environ Sci. (2019);2(I): 8-35. DOI: 10.3088I/aaeoa.000 I9 


\section{and don't think their actions would make a difference.}

The above conclusion of BBC survey, actually reveals the major threats of climate change in Nepal, which are already visible. Most of the concerned stakeholders are aware of climatic threats and worried.

The Government of Nepal has been actively involved in mitigating the impact of climate change and trying to draw international attention and help. Nepal signed the most of international treaties, agreements and active participants, supporter of major climate change deals.

Nepal still lacks the proper instrumental arrangements in addressing the changing scenario of climate regime. However, there is new hope because, now, there is new elected body from local, federal and national level. The current government has full majorities in both houses including federal levels. Hopefully, stable government will be able to fulfill the people aspiration in addressing and minimize the impact of climate change.

Q: In South Asia, Pakistan and India obviously grab the most attention. I would like to start out discussing Pakistan. Most readers know that Pakistan faces severe energy and water shortages, which are a major concern for the Abbasi govt. Can you briefly discuss these issues for our readers and what steps PM Abbasi is taking to address these issues? Aside from energy and water, what, in your opinion, are the most pressing environment/ climate change issues facing Pakistan?

The Islamic Republic of Pakistan shares its boundary with India to the east, Iran and Afghanistan to the west, and China to the north. The country lies between $24^{\circ} \mathrm{N}$ to $37^{\circ} \mathrm{N}$ Latitude and $61^{\circ} \mathrm{E}$ to $75.5^{\circ} \mathrm{E}$ Longitude. Pakistan has a land area of 880,000 square kilometer including Azad Jammu \& Kashmir (AJK) and the Northern Areas (without AJK 796,095 square kilometers) that, along with the coastline along with the Arabian Sea about 1,046 kilometers long, and 22,820 square kilometers of territorial waters and an Exclusive Economic Zone covering about 196,000 square kilometers in the Arabian Sea (borders with Afghanistan 2,430 kilometers; China 523 kilometers; India 2,912 kilometers; and Iran 909 kilometers). Pakistan's dominant geomorphic features include the Indus River and its drainage basin. From the mouths of Indus near the Tropic of Cancer, Pakistan extends about 1,700 km to the river's sources in the Himalayan, Hindu Kush, and Karakorum mountains, where several peaks exceed 8,000 meters in height. ${ }^{64}$

Pakistan has varieties climatic variation due to its unique location. It constitutes a broad latitudinal spread, and immense altitudinal range, and number of the world's broad ecological regions, as defined by various classification systems. It contains areas that fall under three of the world's eight biogeography "realms" (Indo-Malayan, Pale arctic, and Afro-tropical); four of the world's ten "biomes" (desert, temperate grassland, tropical seasonal forest, and mountain); and three of the world's four "domains" (polar or mountain, humid-temperate, and dry). The great variety of landscapes, including rangeland, forest, wetland, and other wildlife habitats has generated a rich diversity of life forms. However, among the south Asian countries Pakistan holds the least varieties of biodiversity. ${ }^{64-67}$ As it has verities of climatic zones, Pakistan faces severe energy and water shortages as well as various climatic hazards throughout the history. ${ }^{68}$ It is highly vulnerable to disasters caused by Climate Change, and especially prone to floods and droughts. Sandstorms, dust storms, micro-cloudbursts, cyclones and tsunamis are additional threats. ${ }^{67}$ The major climatic hazards in Pakistan can be seen in Table 4.
Table 4 Climatic Hazards in Pakistan. ${ }^{67}$

\begin{tabular}{ll}
\hline Natural Hazards & Human Induced Hazards \\
\hline Earthquakes & Transport accidents \\
Floods & Oil spills \\
Tsunami & Urban fires \\
Avalanches & Civil conflicts \\
Landslides & International displacements \\
Cyclones/Storms & Radiological (CNR) \\
Glacial Lake Outburst Floods & Accidents \\
(GLOF) & \\
Droughts & \\
River erosion & \\
Pest attacks & \\
\hline
\end{tabular}

Pakistan has been facing severe problem due to the climatic extreme events such as Earthquakes, Floods, Landslides, Cyclones/Storms, Droughts, River erosion, Glacial Lake Outburst Floods (GLOF) etc. and experiencing human causality, displacement and loss of property. For example, in July and August 2010 due to extreme flood more than 1600 people were killed and 14 million became homeless and 170 million people were affected, destroyed 1,226,678 houses (National Disaster Management Authority 2010) and damaged about a trilliondollar worth of property and infrastructures of the country (United Nations Office for the Coordination of Humanitarian Affairs-OCHA 2010). This flood has been considered one of the worst natural disasters of Pakistani history which affected to entire nation. As published in various news sources: The United Nations has rated the floods in Pakistan as the greatest humanitarian crisis in recent history with more people affected than the South-East Asian tsunami and the recent earthquakes in Kashmir and Haiti combined. Maurizio Giuliano, a spokesman for the UN Office for the Coordination of Humanitarian Affairs (OCHA) said: This disaster is worse than the tsunami, the 2005 Pakistan earthquake and the Haiti earthquake. ${ }^{69-71}$ According to Pakistan's National Disaster Management Authority (NDMA), the affected area covers $132,421 \mathrm{~km}$, including 1.4 million acres of cropped land. ${ }^{72}$

As other Asian countries, Pakistan is facing similar environmental problems such as deforestation, air pollution, water pollution, noise pollution, climate change, pesticide misuse, soil erosion, natural disasters and desertification. However, noticeable problems are waste management and water crisis. The few pictures (from various news sources) show the reality of the fact. The following pictures show Karachi's garbage problem ${ }^{73,74}$ :

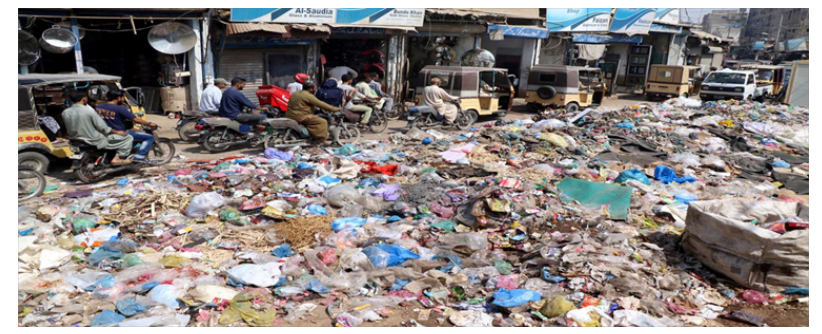

The following is an excerpt from "Pakistan's Water Crisis:Why a National Water Policy is Needed."75
Submit your Article | www.ologyjournals.com/submit-article OP Ology $f$ in $y$ rifite
Citation: Bhandari MP. "BashudaivaKutumbakkam"-The entire world is our home and all living beings are our relatives. Why we need to worry about climate change, with reference to pollution problems in the major cities of India, Nepal, Bangladesh and Pakistan. Adv Agr Environ Sci. (2019);2(I): 8-35. DOI: 10.3088I/aaeoa.000I9 

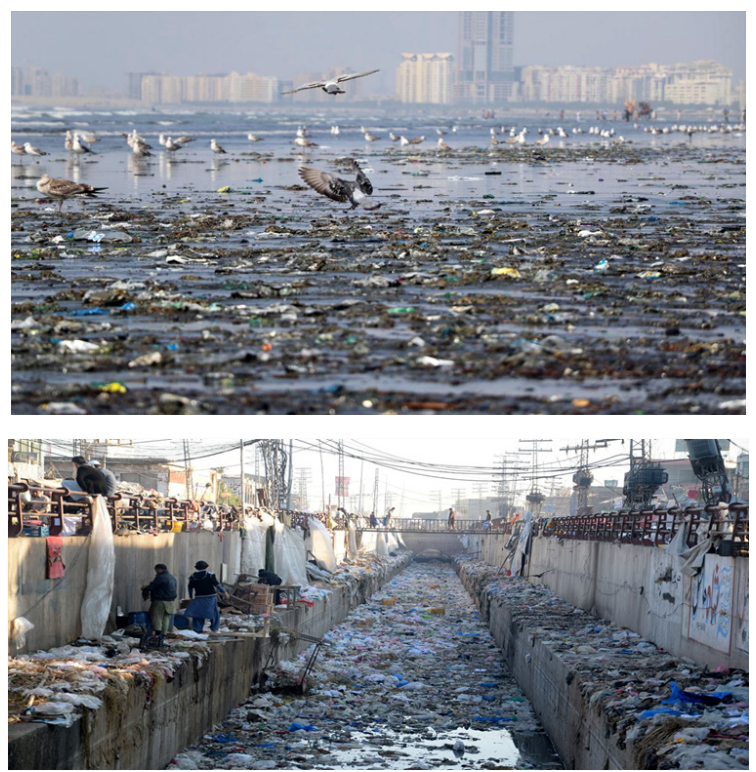

Recently, the Pakistan Council of Research in Water Resources (PCRWR) delivered a grave warning: if the government does not take action, the country will run out of water by 2025. Severe water scarcity is already having a negative impact on the country's public health and the economy. Over 80 percent of water supplied is considered unsafe, and water scarcity and waterborne diseases are resulting in a loss of up to 1.44 percent of GDP.

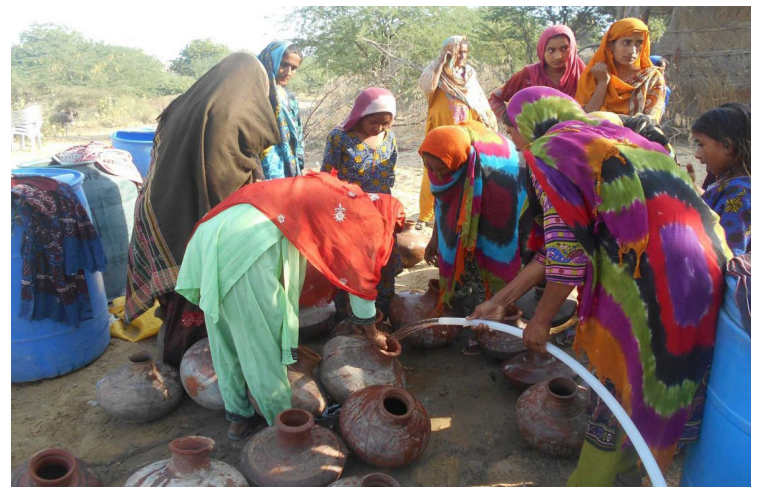

Women gather water at a central drinking pump. Severe water scarcity in Pakistan is already having a negative impact on the country's public health and the economy, with over 80 percent of water supplied in the country is considered unsafe.

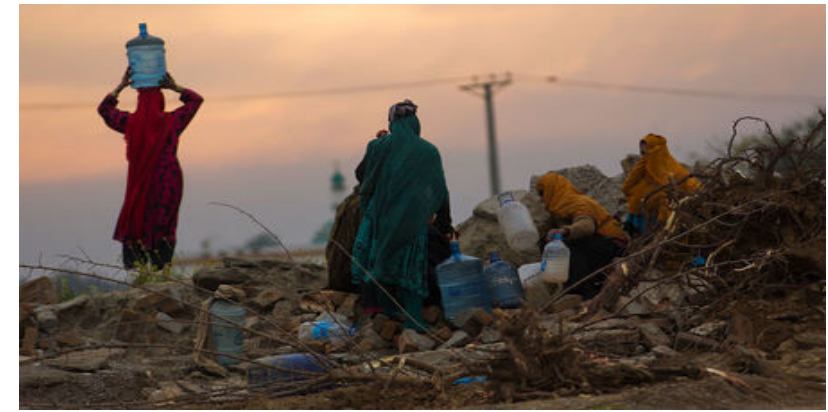

Villagers collect water from a broken water pipeline in the outskirts of Islamabad.

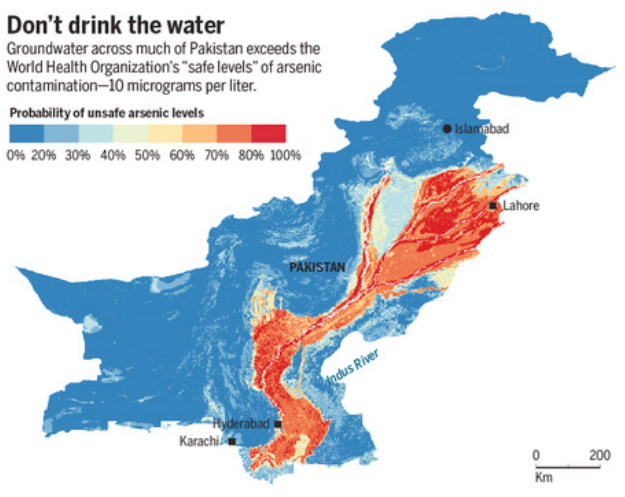

\section{JIA YOU/SCIENCE}

Arsenic in drinking water threatens up to 60 million in Pakistan. ${ }^{76}$

The above pictures nicely depict the severity of the climate change in Pakistan. The government, the general public, the international organizations (all concern stakeholders) are aware of the problems and also working to minimize the devastating impacts. The following will show what people are doing to overcome with this devastating problem through plantations.

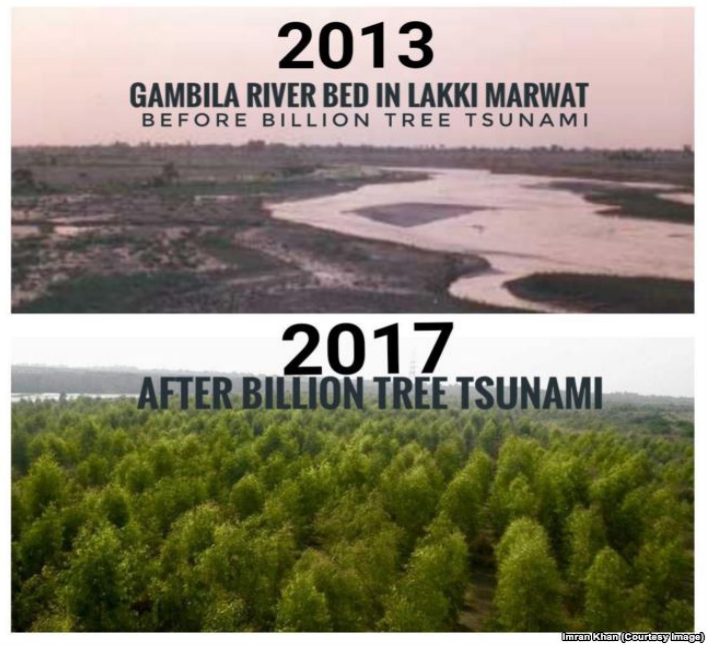

One Billion Trees Planted in Pakistan's NW Province: Pakistan's northwestern province. Khyber Pakhtunkhaw (KPK), has planted an unprecedented 1 billion trees in just more than two years and surpassed an international commitment of restoring 350,000 hectares of forests and degraded land..$^{77}$

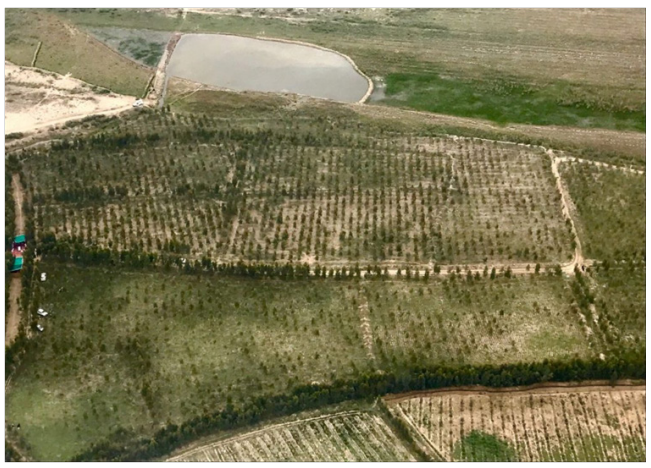

Citation: Bhandari MP. "BashudaivaKutumbakkam"- The entire world is our home and all living beings are our relatives. Why we need to worry about climate change, with reference to pollution problems in the major cities of India, Nepal, Bangladesh and Pakistan. Adv Agr Environ Sci. (2019);2(I): 8-35. DOI: I0.3088I/aaeoa.000 I9 


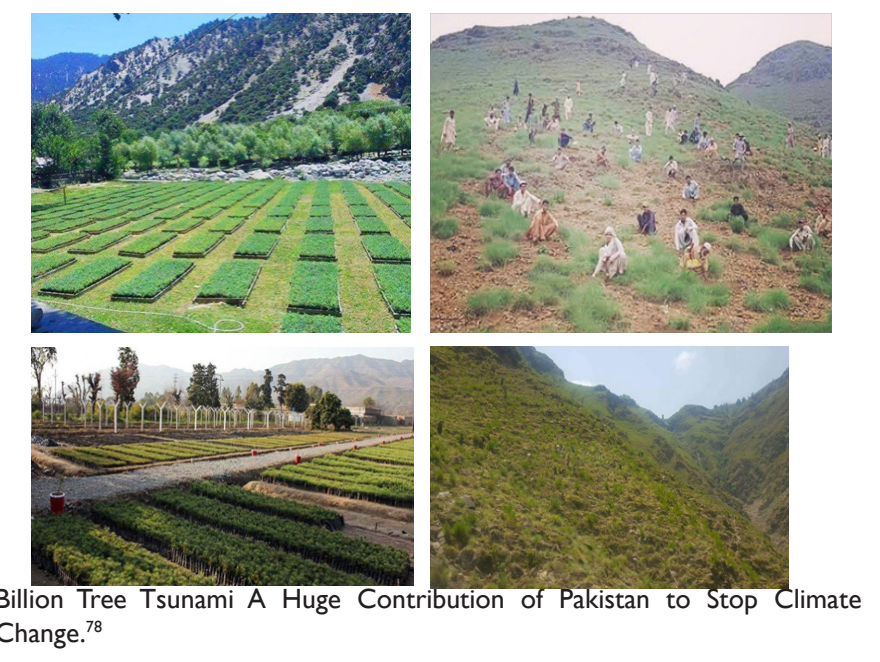

The above images are from the article, "Billion Tree Tsunami a Huge Contribution of Pakistan to Stop Climate Change." The initiative was launched in 2013 and since then more than $75 \%$ of the 1 billion trees have been planted in the province. We often hear about the global climate change and its negative impacts on our planet. New initiatives are being taken all over the world in an effort to reverse this climate change. One such initiative is taken by the Khyber Pakhtunkhwa province of Pakistan. This mega initiative is given the name of Billion Tree Tsunami. According to the details of this initiative, the government of Khyber Pakhtunkhwa province in Pakistan is planting 1 billion trees. The best thing about this project is that more than $75 \%$ trees have already been planted and are growing rapidly. These illustrated initiatives are only few examples. There are such programs in each province and districts.

The Government of Pakistan has been taking climate change issue seriously. In its report to the UNFCC in 2001 and taskforce report of 2010 , it repeats that, because climate change is posing a direct threat to its water security, food security and energy security. ${ }^{79,80}$ There are several national level policy commitments in addressing the degrading environmental situation of the country. Pakistan has been a party to various Environmental Conventions and Protocols. To evaluate the climate change issue regularly the Government of Pakistan launched a comprehensive program called "SMART" (self-Monitoring and Reporting Tool) with the help of Sustainable Development Policy Institute (SDPI), which was founded by the government to address the issues of sustainable development, environment and climate change, which helps to monitor release of effluents and emissions from the Industries initially with 50 industrial Units later expending to 200 and 400 Industrial Units all across the country under phase-I program. ${ }^{81,82}$ There have been several projects running in Pakistan to address the climate change issue in the country with the financial and technical support of various international organizations i.e. the World Bank, Asian Development Bank, GTZ, DFID, UN agencies, the IUCN, the WWF etc. ${ }^{81-83}$ In addition to Government's plan, policies and projects, the government established institutions, agencies as well as international organizations also have been working to address the climate change issues in Pakistan.

The scenario clearly indicates that the government of Pakistan is serious in addressing the degrading environmental situation and impact of climate change, through its national and international commitments. The following section elaborates on Pakistan's involvement on international treaties, convention and conferences including climate change. However, the global context, Pakistan has signed only about
16 percent of bounding treaties related to environment and climate change. In addition to showing its commitments in the international and national policy instruments, the government of Pakistan has been maintaining it memberships with the numerous of International Organizations.

Q: We can't discuss South Asia without talking about India. It's the largest, wealthiest, most industrialized nation in South Asia. Yet, it does have severe problems. Smog blankets most cities, sporadic electricity, troubles with its rail network and mass transit, the list is almost endless. In your opinion, what are the most serious issues facing India today, and what steps is the Modi government taking to address these issues?

As I noted, in the first section of this interview, India holds second largest population in the world and seventh largest in terms of geographical territory. Yes, India has ample of opportunities and threats. I think, the geographical wealth and abundance and its large population is also opportunity, strength and key of innovation, for industrialization and growth. It is established notion that, there are negative side effects of over population and industrialization. The pollution, waste, increase of environmental health risk, transit and traffic issues can be an account of a few examples of such side effects. However, it has long history to tackle issues, which still remain strongly influential in Indian rich culture and traditions.

"India has a civilizational legacy which treats Nature as a source of nurture and not as a dark force to be conquered and harnessed to human Endeavour. There is a high value placed in our culture to the concept of living in harmony with Nature, recognizing the delicate threads of common destiny that hold our universe together. The time has come for us to draw deep from this tradition and launch India and its billion people on a path of ecologically sustainable development" (Dr. Manamohan Singh. Prime Minister of India, June 30, 2008) (44 $^{84}$

"India is the cradle of human race, the birthplace of human speech, the mother of history, the grandmother of legend, and the great grandmother of tradition. Our most valuable and most astrictive materials in the history of man are treasured up in India only." (Mark Twain)

Environmental protection was cast as a citizen's duty and as a part of the people's spiritual lives, which can be found in all major religious epic, grew in India. Examples of the spiritual importance of environmental protection can be drawn from the Hindu, Islamic and Buddhist theologies. The five principles of Buddhism are as follows: abstinence from killing all forms of life; abstinence from sexual misconduct; abstinence from lies and deceit; abstinence from theft and abstinence from intoxicants. The first principle clearly point to the importance of the conservation of all living beings. Similarly, in Islam "the conservation of the environment is based on the principle that all the individual components of the environment were created by God, and that all living things were created with different functions, functions carefully measured and meticulously balanced by the Almighty Creator. Although the various components of the natural environment serve humanity as one of their functions, this does not imply that human use is the sole reason for their creation. ..." $" 85$ In the major Hindu epics, such as the Vedas, Puranas, Upanishads, and others, there are detailed descriptions of the trees, plants and wildlife and their importance to the people. "The Rig Veda highlighted the potentialities of nature in controlling the climate, increasing fertility and improvement of human life emphasizing on intimate kinship with nature. Atharva Veda considered trees as abode of various gods and goddesses. Yajur Veda Emphasized that the relationship with nature and the animals should not be that of dominion and subjugation but of mutual respect and kindness. Many animals and plants were
Submit your Article | www.ologyjournals.com/submit-article

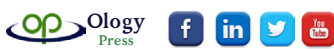

Citation: Bhandari MP. "BashudaivaKutumbakkam"-The entire world is our home and all living beings are our relatives. Why we need to worry about climate change, with reference to pollution problems in the major cities of India, Nepal, Bangladesh and Pakistan. Adv Agr Environ Sci. (2019);2(I): 8-35. DOI: 10.3088I/aaeoa.000I9 
associated with Gods and Goddesses so that they were preserved for the future generations. As they were associated with supernatural powers, no one dared to misuse the resources and therefore there was a check on the excess utilization of resources." ${ }^{17-89}$

India holds the most influential role in South Asia: it has the oldest and most extensive history of civilization, colonization, and struggle for independence, as well as an extended democratic system and the second largest population on the globe. Pakistan and Bangladesh were part of India until they became independent; therefore, these two countries have been following a similar tradition of conservation bureaucracy as India. India's influence in modern Nepal is even stronger than in Pakistan and Bangladesh because India and Nepal share an open border and citizens of both countries do not require work permits. Similarly, Nepal and India have the largest Hindu population and therefore have strong cultural ties. Because of these facts, to some extent an understanding of India in general reflects an understanding of the other three nations.

As India has all kind of ecosystems and diversities, it has also verities of environmental problems. The following list from Mahesh Chandra ${ }^{90}$ provides a nice summary:

- Air pollution from industrial effluents and vehicle emissions;

- Energy-related environmental problems such as, chemical \& oil pollution and Greenhouse Gas (GHG) emissions (Greenstone and Hanna, 2014);

- Water pollution from raw sewage, the lack of adequate sanitation, and nonportable water throughout the country;

- Municipal solid waste management (MSWM) remains a challenge for India due to the rising population and the resultant infrastructural needs (Dube, Nandan, and Dua, 2014);

- Over-population and its strain on natural resources; and

- Agricultural factors such as, runoff of agricultural pesticides, overgrazing, short cultivation cycles, slash and burn practices, destructive logging practices, and deforestation of timber reserves for fuel, all contribute conjointly to the decimation of the subcontinent's environmental system.

There are area specific problems in terms of pollution, waste, sewages, over population, poverty. The following few excerpts (published in various newspaper illustrate few examples).

The key environmental challenges facing India today include (i) air pollution; (ii) poor management of waste; (iii) growing water scarcity; (iv) declining levels of groundwater; (v) water pollution; (vi) forest preservation and quality; (vii) loss of biodiversity; (viii) land and soil degradation; and (ix) increasing frequency of natural disasters, including droughts and floods. Coupled with the demands of India's increasing population, these challenges place mounting pressure on India's environmental resources. Growth of India's economy will place further pressures on India's natural resource base, and reinforce the need to sustainably exploit and manage these resources. This is particularly important because India's poor suffer most from declining natural resource productivity. ${ }^{91}$

Breathing in the Indian capital this month was like smoking 50 cigarettes a day. On November 8, pollution surged so high that some monitoring stations reported an Air Quality Index of 999, way above the upper limit of the worst category, Hazardous. (An extra-sensitive air quality instrument at the US embassy got a reading of 1,010, as you can see in the chart below. $)^{92}$

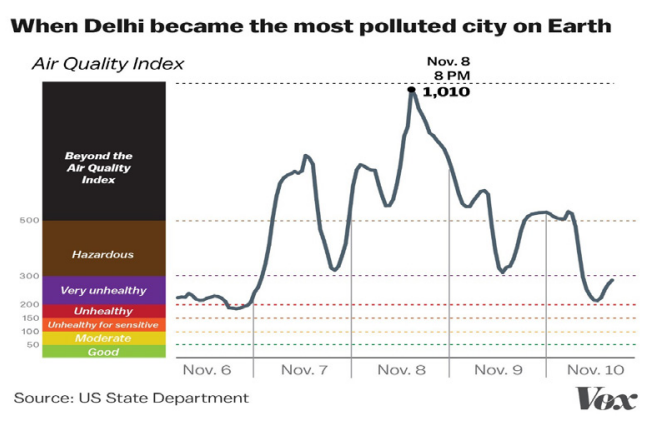

Rural Indians, who make up about two-thirds of the country of 1.3 billion people, are disproportionately at risk of breathing polluted air, according to new research. India's air pollution has been making headlines for years, with attention focused on Delhi, the capital, once named the most polluted city in the world by the World Health Organization. ${ }^{93}$

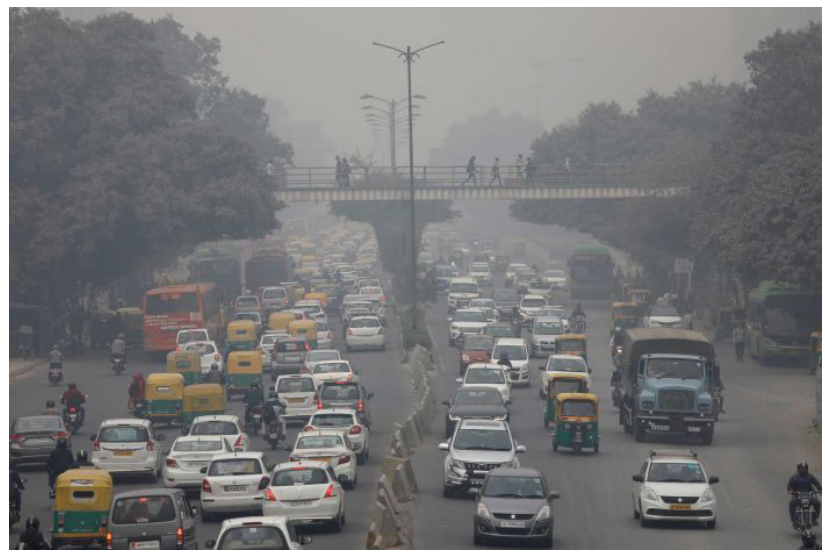

India's air pollution crisis risks becoming humanitarian catastrophe. Vehicles drive through smog in New Delhi. ${ }^{94}$

As there are countless many problems, however, as its culture and tradition indicates, there are numerous efforts are also taking place to overcome from such problems. For example, India is signatory of most of the environment related treaties and conventions. India's Constitution, Article 51(c), sets the directive principle requiring the State to foster respect for International law and treaty obligations ${ }^{95}$ India first accepted the impact of climate change after the 1947 publication of Sisir Kumar Mitra's book titled The Upper Atmosphere, published by Calcutta, Royal Asiatic Society of Bengal. "He considered, for the first time, the atmospheric environment as a whole-neutral and ionized - its thermal structure and distribution of constituents, its motions, the interaction of the solar radiation and the particle streams from the sun with these constituents. He also considered the atmosphere from the surface to the fringe of the upper atmosphere." $" 96$

As guided and accepted by the constitution of India, there are many initiates, government of India and even general public have been working to minimize the impact of environmental change, throughout the history, with some disputes on natural resource management.

"Nature-based conflicts have increased in frequency and intensity in India. They revolve around competing claims over forests, land, water and fisheries, and have generated a new movement struggling for the rights of victims of ecological degradation. The environmental
Citation: Bhandari MP. "BashudaivaKutumbakkam"- The entire world is our home and all living beings are our relatives. Why we need to worry about climate change, with reference to pollution problems in the major cities of India, Nepal, Bangladesh and Pakistan. Adv Agr Environ Sci. (2019);2(I): 8-35. DOI: I0.3088I/aaeoa.000 I9 
movement has added a new dimension to Indian democracy and civil society. It also poses an ideological challenge to the dominant notions of the meaning, content and patterns of development." 97

However, together with government, general public are looking options to overcome with the increasing problems due to environment degradation. The following are excerpts from news sources:

Government has Taken Series of Steps to Address Pollution-Related Issues: Environment Minister ${ }^{98}$

Pollution is a matter of concern in cities and towns and is caused due to introduction of contaminants into the environment viz. air, water and soil that may cause adverse change in ambient conditions. The Government has taken a series of steps to address issues related to water pollution, air \& vehicular pollution, industrial pollution, improper waste disposal etc. in cities, towns and metropolises.

The major steps being taken by the Government to control pollution inter alia include the following:-

(i) Notification of National Ambient Air Quality Standards;

(ii) Formulation of environmental regulations / statutes,

(iii) Setting up of monitoring network for assessment of ambient air quality;

(iv) Introduction of cleaner / alternate fuels like gaseous fuel (CNG, LPG etc.), ethanol blend etc.;

(v) Promotion of cleaner production processes.

(vi) Launching of National Air Quality index by the Prime Minister in April, 2015;

(vii) Implementation of Bharat Stage IV (BS-IV) norms in 63 selected cities and universalization of BS-IV by 2017;

(xix) Implementation of National River Conservation Plan for abatement of pollution in identified stretches of various rivers and undertaking conservation activities...

\section{India: Country Partnership Strategy 2013-2017}

The government has taken steps to mainstream both climate change mitigation and adaptation within its developmental framework through policies and action plans. India's Eleventh Five Year Plan (2007-2012) recognized the urgent need to balance the growthenvironment tradeoff, given the dangers posed by India's large population, economic growth, and ever-increasing demands on natural resources including water. India has made admirable efforts on its climate change program through the National Action Plan on Climate Change (NAPCC). In response to the NAPCC, all Indian states have been directed to prepare a state climate change action plan (SCAP), detailing sector-specific plans to adapt to and mitigate climate change. A few states have already initiated studies to prepare their state's climate action plans, and aim to identify the most vulnerable sectors and regions to projected climate change and to develop adaptation projects. These action plans also aim to assess GHG emissions and identify potential mitigation programs and projects.

India launched its NAPCC in June 2008, and has established eight national missions to address various aspects of climate change mitigation and adaptation: (i) solar energy, (ii) enhanced energy efficiency, (iii) sustainable habitats, (iv) water, (v) sustaining the Himalayan ecosystem, (vi) national mission for a green India, (vii) national mission for sustainable agriculture, and (viii) strategic knowledge for climate change. ADB has been at the forefront of supporting some of these missions and mainstreaming climate change adaptation and mitigation concerns into its operations, in line with
India's Twelfth Five Year Plan. The latter emphasizes mainstreaming of climate change interventions across sectors and supports the development of SCAPs that may be dovetailed into the NAPCC by developing specific action programs for sector operations to facilitate mitigation and adaptation action against the challenge of climate change. Source: ADB-https://www.adb.org/sites/default/files/linkeddocuments/cps-ind-2013-2017-ena.pdf

India plants 66 million trees in 12 hours as part of record-breaking environmental campaign

More than 1.5 million volunteers were involved in the huge operation $^{99}$

"Volunteers in India planted more than 66 million trees in just 12 hours in a record-breaking environmental drive. About 1.5 million people were involved in the huge plantation campaign, in which saplings were placed along the Narmada river in the state of Madhya Pradesh throughout Sunday. India committed under the Paris Agreement to increasing its forests by five million hectares before 2030 to combat climate change".

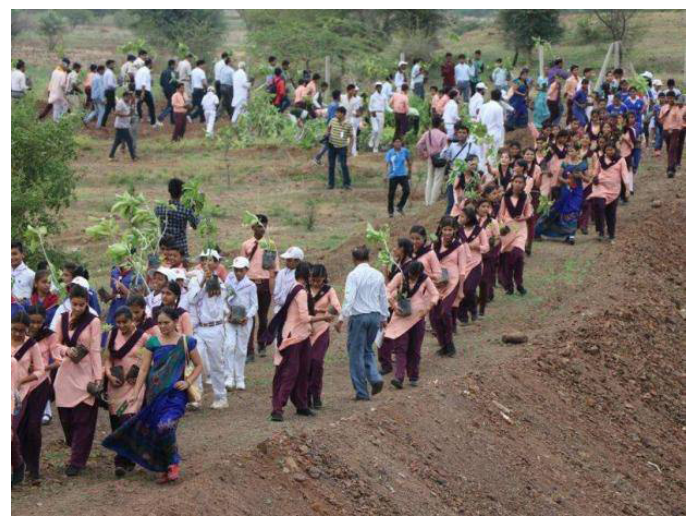

6 Important Eco-Friendly Steps Taken by Narendra Modi Government ${ }^{100}$

(1) Swachh Bharat Abhiyan: The Swachh Bharat Abhiyan is India's biggest cleanliness drive ever. The campaign covers as many as 4041 towns and aims at cleaning streets, roads, and infrastructure.

(2) Clean Ganga Mission: Modi's Clean Ganga Plan involves five ministries working in close co-operation to see the dream project through.

(3) National Air Quality Index (NAQI): The NAQI will simplify air quality rendition and will help raise awareness about alarming levels of air quality across the country.

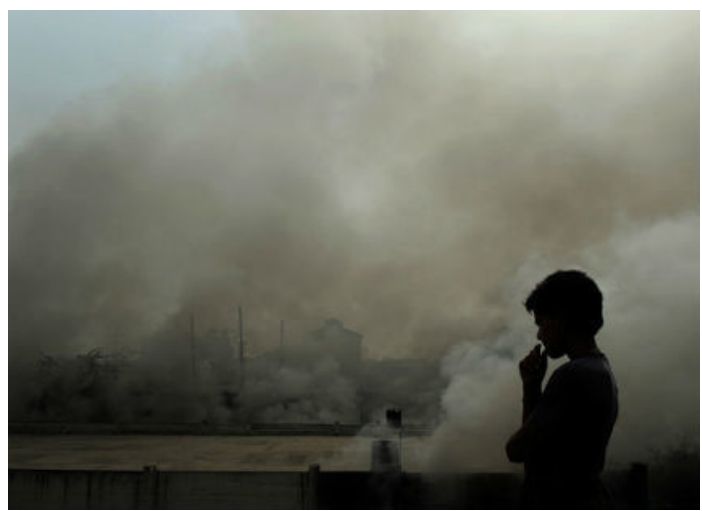

Submit your Article | www.ologyjournals.com/submit-article OP Ology
Citation: Bhandari MP. "BashudaivaKutumbakkam"-The entire world is our home and all living beings are our relatives. Why we need to worry about climate change, with reference to pollution problems in the major cities of India, Nepal, Bangladesh and Pakistan. Adv Agr Environ Sci. (2019);2(I): 8-35. DOI: 10.3088I/aaeoa.000I9 
(4) Toilets Before Temples: Modi government is working tirelessly to ensure that affordable sanitation reaches the people who need it. In addition to this, Modi government has also focused on the spread of e-toilets in rural as well as urban India.

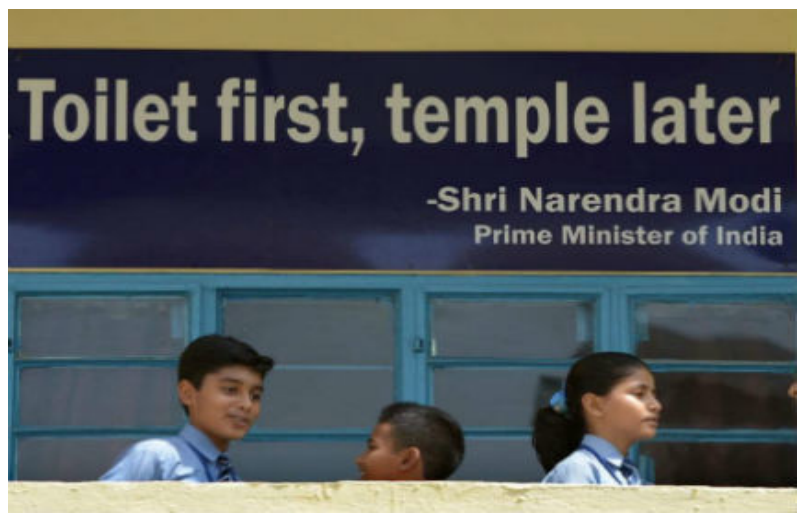

(5) Mount Everest Ascent: Although the Mount Everest cleaning drive is essentially an Indian Army undertaking, authorities have made it clear that they draw inspiration from Narendra Modi's Swacch Bharat Abhiyan. A team of Indian Army climbers have set off on a mission to bring back at least $4000 \mathrm{~kg}$ of non-biodegradable waste from the world's highest peak. This includes waste materials left behind by climbers over decades.

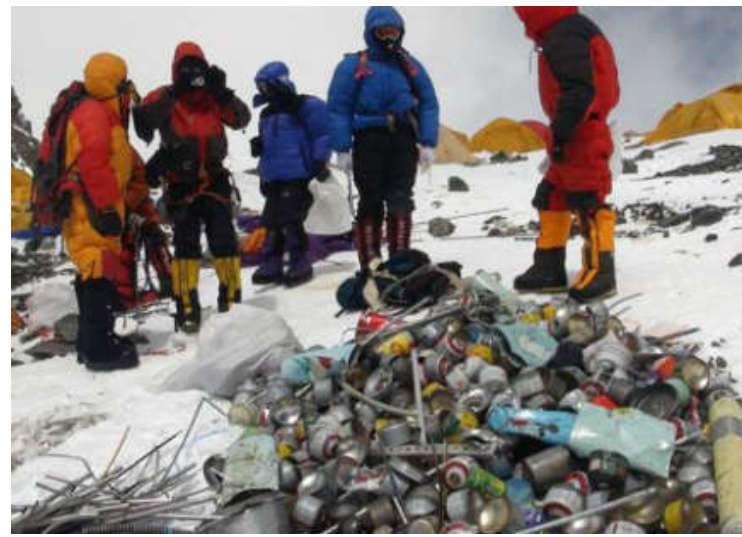

(6) Water Conservation: In a bid to raise awareness about water conservation, the Narendra Modi government directed the states of India to ensure that $50 \%$ of the work taken up by MNREGA, should be for the improvement of water conservation.

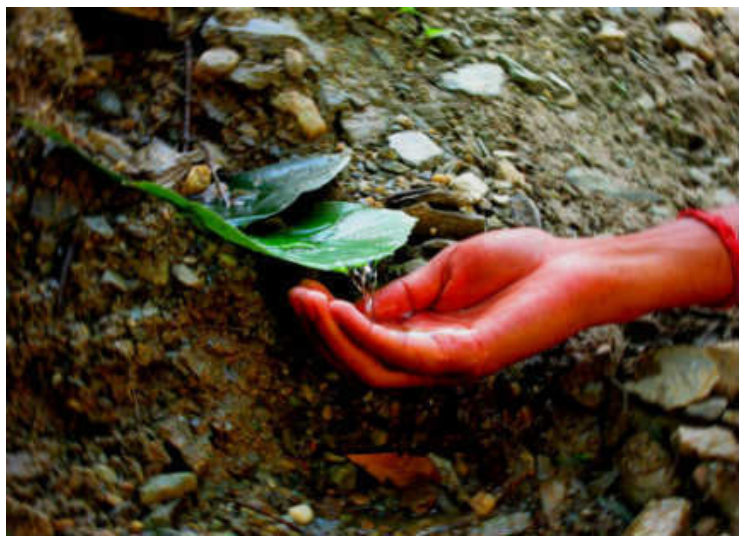

The listed texts and figures give some general outlines of what government is doing to address the severity of the environment induced problems in India. There may be less practical work, than, whatever is advertised in the government publications or in the newspapers to support or oppose the government; however, it clearly indicates that, the government and other concerned stakeholders are aware of the severity of the problems and trying their best to overcome, / minimize the problems.

Theoretically, and in practice to some extent, India is committed to environment conservation, which includes addressing climate change issues, and has been working to develop collaborative plans and projects with the Multilateral Donor Agencies, Development Agencies, Civil Societies and the private sector. India has also shown its firm commitment both domestically and internationally by signing and ratifying the major conventions and treaties related to the environment and climate change, most of which were from the first United Nations Conference on Environment in Stockholm in 1972. ${ }^{101}$ Since the Conference, India has prepared and implemented approximately 40 Acts and Policies. Consequently, India has also established close working networks with the International Network Organization, which includes: the United Nations, IUCN, WWF, Winrock International and climate change. ${ }^{102}$ In addition, India is enforcing the establishment of institutional capacity to incorporate the new policies and acts as needed to address the seriousness of the global environment crisis, which is activating the role of local agencies with the recognition of their contributions.

Q: All governments face difficult policy choices, having to balance environmental/health issues versus national development. This is not unique to Asia. But these policy choices are probably felt more acutely in Asia as the "west" has already achieved a certain level of national development that most nations in Asia are still trying to achieve. How do you feel about the policy choices being made in Nepal, Bangladesh, Pakistan, and India? Are these the optimal choices? Are they the only choices? Or do you think that the governments of South Asia can do better?

As I noted in the earlier sections, the major environmental problems in the region include land degradation \& desertification loss of biodiversity, fresh water depletion \& degradation, solid waste management, degradation of air quality, environmental health issues, degradation and depletion of coastal and marine resources, and natural disasters and their consequences (SACEP 2010). Specifically, they can be summarized in Table 5:
Submit your Article | www.ologyjournals.com/submit-article OP Ology
Citation: Bhandari MP. "BashudaivaKutumbakkam"- The entire world is our home and all living beings are our relatives. Why we need to worry about climate change, with reference to pollution problems in the major cities of India, Nepal, Bangladesh and Pakistan. Adv Agr Environ Sci. (2019);2(I): 8-35. DOI: 10.3088I/aaeoa.000 I9 
Table 5 Key environmental issues and causes. ${ }^{103}$

\begin{tabular}{|c|c|c|}
\hline \multicolumn{3}{|c|}{$\begin{array}{l}\text { Common problems } \\
\text { Climate change and associated } \mathrm{N} \\
\text { development; Coral mining and I }\end{array}$} \\
\hline \multicolumn{3}{|c|}{ Country Specific Problems } \\
\hline Country & Key Issues & Key Causes \\
\hline Bangladesh & $\begin{array}{l}\text { Marginalized populations forced to live on and cultivate flood- } \\
\text { prone land; loss of biodiversity; limited access to potable water; } \\
\text { water-borne diseases prevalent; water pollution, especially of fishing } \\
\text { areas; arsenic pollution of drinking water; urban air pollution; soil } \\
\text { degradation; deforestation; severe overpopulation: natural disasters } \\
\text { (especially floods and cyclones which kill thousands of people and } \\
\text { causes heavy economic losses every year); food security risks; } \\
\text { industrial pollution; import of hazardous waste. }\end{array}$ & $\begin{array}{l}\text { High population density and urban primacy; reliance } \\
\text { on private transport; urbanization and deficits in urban } \\
\text { infrastructure (including one of the world's } 30 \text { largest cities - } \\
\text { Dhaka); increases in unmanaged marine-based tourism; green } \\
\text { revolution/agrochemicals and run-off; high demand for bio- } \\
\text { fuels; lack of controls on industrial effluent; over exploitation } \\
\text { and/or pollution of groundwater. }\end{array}$ \\
\hline India & $\begin{array}{l}\text { Deforestation; soil erosion; overgrazing; desertification; loss of } \\
\text { biodiversity; air pollution; water pollution; huge population base } \\
\text { and large growth rate is overstraining natural resources; natural } \\
\text { disasters such as floods, cyclones and landslides are common; high } \\
\text { death rates and ailments associated with indoor air pollution. }\end{array}$ & $\begin{array}{l}\text { High rates of urbanization and deficits in urban infrastructure } \\
\text { (including in four of world's } 30 \text { largest cities); reliance on } \\
\text { private transport; industrial effluents and vehicle emissions; } \\
\text { increases in unmanaged marine- based tourism; green } \\
\text { revolution/ agrochemicals and run-off; reliance on bio-fuels. }\end{array}$ \\
\hline Nepal & $\begin{array}{l}\text { Deforestation; soil erosion and degradation; loss of biodiversity; } \\
\text { water pollution; natural disasters such as floods and landslides in } \\
\text { rural areas; food security risks }\end{array}$ & $\begin{array}{l}\text { High rates of urbanization; reliance on private transport; } \\
\text { increased demands for timber; increased population density } \\
\text { and cultivation of marginal lands. }\end{array}$ \\
\hline Pakistan & $\begin{array}{l}\text { Water pollution; seasonal limitations on the availability of natural } \\
\text { freshwater resources; majority of the population lacks access } \\
\text { to potable water; deforestation; soil erosion; coastal habitat loss } \\
\text { and degradation of marine environment; desertification; loss of } \\
\text { biodiversity: natural disasters, mainly due to floods. }\end{array}$ & $\begin{array}{l}\text { High rates of urbanization and deficits in urban infrastructure; } \\
\text { industrial wastes; population increases in coastal areas and } \\
\text { rise in tourism; depletion of mangroves for aquaculture; } \\
\text { overfishing; increased demands for timber/bio-fuels; hunting/ } \\
\text { poaching; green revolution/agrochemicals and run-off. }\end{array}$ \\
\hline
\end{tabular}

Most of the issues and causes noted in the table are related to the depletion of forest canopy. The major underlying cause is deforestation, which is associated with the public dependency on natural resources for the livelihood. There are also increasing trend of environmental hazards related human health. The environmental health problems can either be due to the lack of access to essential environmental resources (clean air, water, shelter adequate food etc.,) and due to unhealthy and

Table 6 National Priorities on the environmental issues in South Asia. ${ }^{56,103,104}$

\begin{tabular}{|c|c|c|c|c|}
\hline Land degradation and desertification & $\begin{array}{l}\text { Bangladesh } \\
\text { Priority }\end{array}$ & $\begin{array}{l}\text { India } \\
\text { Priority } \\
\end{array}$ & $\begin{array}{l}\text { Nepal } \\
\text { Priority }\end{array}$ & $\begin{array}{l}\text { Pakistan } \\
\text { Priority } \\
\end{array}$ \\
\hline Water erosion & High & High & High & High \\
\hline Water logging & Medium & Medium & Low & Low \\
\hline Salinization & High & Medium & Low & Medium \\
\hline Loss of Biodiversity & High & High & High & High \\
\hline Deforestation & High & Low & High & High \\
\hline Water scarcity & Medium & Low & Low & High \\
\hline Water Pollution & High & Medium & High & Medium \\
\hline Need for Water supply \& sanitation & High & High & High & Medium \\
\hline Solid \& liquid waste Management in urban centers & High & High & High & High \\
\hline \multicolumn{5}{|l|}{ Degradation of Air quality } \\
\hline Vehicular emission in urban centers & High & High & High & High \\
\hline Industrial emission & Medium & Low & N/A & Medium \\
\hline Domestic cooking & Medium & High & High & High \\
\hline Environmental Health issues & High & High & High & High \\
\hline Depletion and degradation of Coastal \& Marine Environment & High & Medium & N/A & Medium \\
\hline \multicolumn{5}{|l|}{ Natural disasters } \\
\hline Droughts & Medium & Low & Medium & Medium \\
\hline Floods \& Land slides & High & High & High & Low \\
\hline Earth Quakes & Low & Medium & High & Low \\
\hline Sea level rise & Medium & Medium & N/A & High \\
\hline
\end{tabular}

unsafe work environments. Health issues in the form of premature death, chronic bronchitis and other respiratory symptoms are high in several metropolitan centers in the region. The Asian countries are aware on the issues and have kept on the high priority to address them, by principle and practice. Table 6 summarizes environmental issues in South Asia. 
In Summary, each of the four countries has given high priority for the overall conservation of natural resources, including wetlands and introduced or being prepared the strong policies and programs to stop further degradation of nature. Among them, India has the established system of conservation mechanism; however, in terms of policy implementation and conservation, Nepal has shown the exemplary cases of natural resource management with the application of the public participation machineries. Bangladesh and Pakistan performance in conservation is relatively weak, even having very strong involvement of international organization to improve their situation. In addressing the conservation problems, there have been some efforts in the region, coordinated by various organizations such as The South Asian Association for Regional Cooperation (SAARC), Bay of Bengal Initiative for Multi Sectoral Technical and Economic Cooperation (BIMSTEC- Sub Regional mechanism for selected South-South East Asian Member Countries Member Countries: Bangladesh, India, Myanmar, Sri Lanka, Thailand, Bhutan, Nepal), Asian Disaster Reduction and Response Network (ADRRN), IUCN regional office, UN Agency Regional Office, and several other international organization. Among them SAARC's initiatives is very important to address the conservation problems which hold the regional issues particularly, water resources and climate change.

Q: We really do want to thank you for taking the time to share your thoughts and experiences with us. This has been an absolute pleasure for me talking to you and I am sure that our many readers will enjoy your insights into South Asia.

It is my pleasure to share knowledge and expertise As I noted, earlier, my family, communities, and various societies (wherever I have been), including the nature and culture, traditions combinedly nurtured me, without any expectations. My intention, of life is to give or contribute to the society in fullest whatever I have. I would be more than happy, if readers find this information useful. I am open to engage in any kind of collaborative research, teaching, or any other tasks which can contribute to overcome or minimize the devastating impact of climate change.

I would like to clearly state that, most of the information, I have noted in this interview are based on web-search as well as taken from my published and forth coming books manuscripts:

- Bhandari, Medani P. (2018). Green Web-II: Standards and Perspectives from the IUCN, case studies from India, Nepal, Bangladesh and Pakistan, River Publishers, Denmark / the Netherlands ISBN: 978-87-70220-12-5 (Hardback) 978-8770220-11-8 (eBook). ${ }^{105}$

- Getting the Facts Right: The IPCC and the Role of Science in Managing Climate Change, (under contract) River Publishers, Denmark / the Netherlands

- State of Environment in South Asia-A comparative study of Bangladesh, India, Nepal and Pakistan, with Reference of the conservation intervention

- India: Oldest Civilizations, Oldest Conservation History- and the Mutuality with the International Organizations

- Bangladesh: The Country of over Population and UN's Role to Address the Vulnerable Environment

- IUCNs' the Pioneer for Environment conservation efforts in The Country of Geological Variation and Conflict-Nepal
- The IUCN as Organization of Knowledge- the Roles of Policy formation in the Country of Unrest - Pakistan

Most of the pictures, graphs, tables are taken from the websites. I have tried to provide proper sources, citations, and links of the original sources. However, if I missed to note any source, I apologize in advance to the all concern authors, journalists, government agencies and any other stakeholders whom I have cited in this note.

\section{About Prof. Medani P. Bhandari}

Prof. Medani P. Bhandari completed his M.A. in Anthropology (Tribhuvan University, Nepal), M.Sc. Environmental System Monitoring and Analysis (ITC-The University of Twente, the Netherlands), M.A. Sustainable International Development (Brandeis University, Massachusetts, USA), M.A. and Ph.D. in Sociology (Syracuse University, NY, USA). He is dedicated to conservation of nature and natural resources and social empowerment through research and action project. His purpose of life is to give or contribute to the society fullest through whatever he has, earned, learned or experienced. He has worked with various organizations as consultantUnited Nations Environment Program (UNEP)/Adelaide University, the United Nations Development Program (UNDP), the IUCN, the World Wildlife Fund (WWF), the World Resource Institute (WRI), Winrock International, the Japan Environment Education Forum, and the Pajaro Jai Foundation (PJF), along with others. During 2015-17, he served as a Professor of Natural Resources and Environment at the Arabian Gulf University, Bahrain. Prof. Bhandari has spent most of his career focusing on the Sociological Theories; Environmental Sustainability; Social Inclusion, Climate Change Mitigation and Adaptation; Environmental Health Hazard; Environmental Management; Social Innovation; Developing along the way expertise in Global and International Environmental Politics, Environmental Institutions and Natural Resources Governance; Climate Change Policy and Implementation, Environmental Justice, Sustainable Development; Theory of Natural Resources Governance; Impact Evaluation of Rural Livelihood; International Organizations; Public/ Social Policy; The Non-Profit Sector; Low Carbon Mechanism; Good Governance; Climate Adaptation; REDD Plus; Carbon Financing; Green Economy and Renewable Energy; Nature, Culture and Power. Prof. Bhandari's major teaching and research specialties include: Sociological Theories and Practices; Environmental Health; Social and Environmental research methods; Social and Environmental Innovation; Social and Environmental policies; Climate Change Mitigation and Adaptation; International Environmental Governance; Green Economy; Sustainability and assessment of the Economic, Social and Environmental impacts on society and nature. In brief, Prof. Bhandari has sound theoretical and practical knowledge in social science and environment science. His field experience spans across Asia, Africa, the North America, Western Europe, Australia, Japan and the Middle East. Professor Bhandari has published 4 books, and about 50 scholarly papers in international scientific journals. Currently, he is serving as a Professor of Inter-Disciplinary Department - Natural Resource \& Environment / Sustainability Studies, at the Akamai University, USA and Professor of the Department of Finance and Entrepreneurship, Sumy State University (SSU) Ukraine; and International Program Coordinator, Atlantic State Legal Foundation, NY, USA (remotely).

\section{Acknowledgement}

It is my pleasure to share knowledge and expertise on the issues of environmental protection and climate change.My family, all relatives, my network friends and colleagues, communities, and various societies (wherever I have been), including the nature and culture,
Submit your Article | www.ologyjournals.com/submit-article

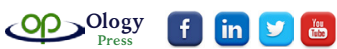

Citation: Bhandari MP. "BashudaivaKutumbakkam"- The entire world is our home and all living beings are our relatives. Why we need to worry about climate change, with reference to pollution problems in the major cities of India, Nepal, Bangladesh and Pakistan. Adv Agr Environ Sci. (2019);2(I): 8-35. DOI: 10.3088I/aaeoa.000I9 
traditions combinedly nurtured, taught me, without any expectations. My intention, of life is to pay back; give or contribute to the society in fullest whatever I have, earned, or experienced. And I have tried to answer, why I am motivated to devote myself within the domain of environmental protection and climate change. I would be more than happy, if readers find this information useful. I am open to engage in any kind of collaborative research, teaching, or any other tasks which can contribute to overcome or minimize the devastating impact of climate change.I would like to clearly state that, most of the information, I have stated inthis interview / discussionare based on web-search, secondary sources, as well as based on my published papers or forth coming books manuscripts, i.e. Green Web-II: Standards and Perspectives from the IUCN-the case studies from India, Nepal, Bangladesh and Pakistan, River Publishers, Denmark / the Netherlands ISBN: 978-87-70220-12-5 (Hardback) 978-87-7022011-8 (eBook).", Getting the Facts Right: The IPCC and the Role of Science in Managing Climate Change, State of Environment in South Asia-A comparative study of Bangladesh, India, Nepal and Pakistan, with Reference of the conservation intervention. Most of the pictures, graphs, tables are taken from the websites. I have tried to provide proper sources, citations, and links of the original sources. However, if I missed to note any source, I request to forgive me and apologize in advance to the all concern authors, journalists, government agencies and any other stakeholders whom I have cited in this note.

\section{References}

1. Kleinschmit J. Agriculture and Climate-the critical connection. Inst Agric Trade Policy. 2009.

2. Environment definition. BusinessDictionary.com. Accessed February 27, 2019

3. Pachauri RK, Allen MR, Barros VR, et al. Climate Change 2014: Synthesis Report. Contribution of Working Groups I, II and III to the Fifth Assessment Report of the Intergovernmental Panel on Climate Change. IPCC; 2014.

4. Khusi Rai Facebook Photos.

5. Facebook

6. Shanti Patha Mantra. Accessed February 27, 2019.

7. Palmer M, Finlay V. Faith in Conservation: New Approaches to Religions and the Environment. 2003.

8. Father's day in Nepal - We All Nepali. Accessed February 27, 2019.

9. Desmostachya bipinnata. In: Wikipedia. ; 2018. Accessed February 27, 2019.

10. Pterocarpus santalinus. In: Wikipedia. ; 2019. Accessed February 27, 2019.

11. Benefit of Rudraksha. Accessed February 27, 2019.

12. Rudraksha. In: Wikipedia. ; 2019. Accessed February 27, 2019.

13. Ziziphus budhensis. In: Wikipedia. ; 2018. Accessed February 27, 2019.

14. Buddha chitta mala. In: Wikipedia. ; 2018. Accessed February 27, 2019

15. WD. जानए शुभ कारयों में पंच यानी 5 का महत्त्व. http://hindi.webdunia.com/ astrology-articles/importance-of-five-113122600061_1.html. Accessed February 27, 2019.

16. Saraca asoca. In: Wikipedia. ; 2019. Accessed February 27, 2019.

17. Banyan | plant. Encyclopedia Britannica. Accessed February 27, 2019.

18. Ficus religiosa. In: Wikipedia. ; 2019. Accessed February 27, 2019.

19. Silwal M. English: Bar-Pipal Trees at Basantapur, Kathmandu: The Holy
Trees of Hindus Generally Planted Side by Side.; 2013. Accessed February $27,2019$.

20. Association for Protection of Environment and Culture (APEC-NEPAL) An Introduction. Accessed February 27, 2019.

21. List of 30 Top Environmental Concerns | LoveToKnow. Accessed February 27, 2019.

22. Cieslikowski D. World Development Indicators 2008. The World Bank; 2009:1-460. Accessed February 27, 2019.

23. OMS. World Health Statistics 2009. Suiza: World Health Organization; 2009.

24. Sup Lee S. World Development Indicators 2010. The World Bank; 2010:1492. Accessed February 27, 2019.

25. Bank W. World Development Indicators 2011. The World Bank; 2011:1466. Accessed February 27, 2019.

26. 10 Current Environmental Issues. Conserve Energy Future. November 2013. Accessed February 27, 2019.

27. Landrigan PJ, Fuller R. The impact of pollution on planetary health: emergence of an underappreciated risk factor. UN Environ Programe. (29).

28. Environmental Performance Index. In: Wikipedia. ; 2019. Accessed February 27, 2019.

29. 10 Major Environmental Challenges Faced by India. Accessed February $27,2019$.

30. How climate change plunders the planet. Environmental Defense Fund. Accessed February 27, 2019.

31. Ministry of Environment and Forests, Government of Bangladesh. State Of Environment Bangladesh 2001. Accessed July 28, 2010.

32. Climate Change \& its Impacts on Bangladesh. NCDO. Published April 3, 2012. Accessed February 28, 2019.

33. 17 Powerful Images Showing The Devastating Effects Of Overpopulation. Bored Panda. Accessed February 28, 2019.

34. WB: Bangladesh losing 1\% of its GDP every year due to air pollution. Dhaka Tribune.. Published December 10, 2017. Accessed February 28, 2019.

35. Impact of sea level rise in Bangladesh | GRID-Arendal. Accessed February 28, 2019.

36. Brammer H. Bangladesh's dynamic coastal regions and sea-level rise. Clim Risk Manag. 2014;1:51-62. doi:10.1016/j.crm.2013.10.001

37. IPCC. Climate Change: The IPCC Impacts Assessment.; 1990.

38. IPCC. The Regional Impacts of Climate Change. An Assessment of Vulnerability. New York: Cambridge University Press; 1998.

39. IPCC. Climate Change 2001: The Scientific Basis. New York: Cambridge University Press; 2001.

40. IPCC. Climate Change 2001: Impacts, Adaptation and Vulnerability and Mitigation. New York: Cambridge University Press; 2001.

41. Dhaka ranked as the most polluted city. Dhaka Tribune. Published February 23, 2018. Accessed February 28, 2019.

42. The World Bank. Public Attitudes toward Climate Change: Findings from a Multi-Country Poll.; 2009.

43. Ministry of Environment and Forest Government of the People's Republic of Bangladesh. National Adaptation Programme of Action (NAPA). Bangladesh; 2005.
Submit your Article | mww.ologyjournals.com/submit-article OP ${ }_{\text {Press }}^{\text {Ology } f \text { in } y \text { tite }}$
Citation: Bhandari MP. "BashudaivaKutumbakkam"-The entire world is our home and all living beings are our relatives. Why we need to worry about climate change, with reference to pollution problems in the major cities of India, Nepal, Bangladesh and Pakistan. Adv Agr Environ Sci. (2019);2(I): 8-35. DOI: I0.3088I/aaeoa.000I9 
44. Ministry of Environment and Forests Government of the People's Republic of Bangladesh. Bangladesh Climate Change Strategy and Action Plan 2009. Bangladesh; 2009.

45. Nepal's Kathmandu ranks 5th in Pollution Index 2017. https:// thehimalayantimes.com/nepal/nepals-kathmandu-ranks-5th-in-pollutionindex-2017/. Accessed February 28, 2019.

46. Kathmandu Valley: Dust bowl of pollution. The Himalayan Times. Published February 16, 2017. Accessed February 28, 2019.

47. World Environment Day: Campaigners lay dead demanding right to clean air - Valley - The Kathmandu Post. Accessed February 28, 2019.

48. Nepal's air quality is worst in the world: EPI report - Valley - The Kathmandu Post. Accessed February 28, 2019.

49. Republica. Nepal stands as fifth worst country for curbing air pollution. My Republica. Accessed February 28, 2019.

50. After devastating earthquake, Nepal aims to reduce the risk of disaster through green rebuilding. World Wildlife Fund. Accessed February 28, 2019 .

51. Government of Nepal National Planning Commission Secretariat Central Bureau of Statistics. Compendium of Environment Statistics Nepal 2015.; 2015.

52. Rabi Lamichhane Fans sidhakura. Facebook

53. Agrawala S, Raksakulthai V, van Aalst M, Larsen P, Smith J, Reynolds J. Development and Climate Change in Nepal: Focus on Water Resources and Hydropower. Oecd Paris; 2003.

54. Karki MB. Nepal's experience in climate change issues. In: Fourteenth Asia Pacific Seminar on Climate Change, Sydney, Australia.; 2007.

55. Lamichhane BR, Awasthi KD. Changing climate in a mountain subwatershed in Nepal. J For Livelihood. 2009;8(1):99-105.

56. United Nations Environment Programme (UNEP). 2001 Annual Evaluation Report.; 2002.

57. OECD. Annual Report 2003.; 2003.

58. ADB/ICIMOD. Environmental Assessment of Nepal, Emerging Issues and Challenges. Kathmandu: Asian Development Bank and International Centre for Integrated Mountain Development; 2006:55-64.

59. IPCC. AR4 Climate Change 2007: Synthesis Report.; 2007.

60. USA Department of Defense, USA Department of State, USAID. U.S Mission/Kathmandu Country Assistance Strategy 2009-2013.; 2009.

61. Ministry of Forests and Soil Conservation (MOFSC). The Future of Nepals Forests Outlook for 2020. Singh Durbar, Kathmandu; 2007.

62. Colom A, Pradhan S. How the People of Nepal Live with Climate Change and What Communication Can Do. London: BBC Media Action; 2013.

63. Disaster response plans fall flat at flood-hit Biratnagar airport. Accessed February 28, 2019.

64. Asian Development Bank (ABD). Islamic Republic of Pakistan Country Environment Analysis.; 2008.

65. United Nations Environment Programme (UNEP). Global Biodiversity Assessment. Cambridge University Press; 1995.

66. Government of Pakistan Ministry of Environment, Local Government and Rural Development (collaboration with WWF and IUCN). Biodiversity Action Plan for Pakistan. Pakistan; 2000.

67. IUCN, Government of Pakistan Ministry of Environment. Disaster Management in Pakistan.; 2009.
68. Iqbal MM. Vulnerability of Pakistan to Climate Change Hazards. Presented at the: National Disaster Awareness Day 2009; 2009; Islamabad.

69. Tweedie N. Pakistan floods: disaster is the worst in the UN's history. Published August 9, 2010. Accessed February 28, 2019.

70. Pakistan flood aid not getting through - UN.https://www.bbc.com/news/ world-south-asia-10997669. Published August 17, 2010. Accessed February 28, 2019.

71. OCHA. Annual Report 2010.; 2010.

72. Pakistan Floods 2010, Floods in Pakistan, Pakistan Floods Donating and Organizational Relief Campaign Information. The Current Affairs. Published 2010. Accessed August 21, 2010

73. In pictures: Karachi's garbage problem - Pakistan. Dunya News. Accessed February 28, 2019.

74. Keeping trash alive - Herald. https://herald.dawn.com/news/1153824/ keeping-trash-alive. Accessed February 28, 2019.

75. Inderfurth KF, Eliot TL, Jr. Pakistan's Water Crisis: Why a National Water Policy is Needed. Asia Found. November 2017. Accessed February 28, 2019.

76. Guglielmi, G. Arsenic in drinking water threatens up to 60 million in Pakistan. Science | AAAS. Published August 23, 2017.

77. One Billion Trees Planted in Pakistan's NW Province. VOA. Accessed February 28, 2019.

78. Khan H. Billion Tree Tsunami A Huge Contribution of Pakistan to Stop Climate Change. Paki Holic. July 2017. Accessed February 28, 2019.

79. Planning Commission, Government of Pakistan. Final Report of the Task Force on Climate Change. Islamabad, Pakistan; 2010.

80. Ministry of Environment, Local Government and Rural Development. National Report of Pakistan on the Implementation of United Nations Convention to Combat Desertification (UNCCD).; 2001.

81. SDPI. Sustainable Industrial Development / National Environmental Quality Standards. Islamabad, Pakistan: Sustainable Development Policy Institute; 2006. Sustainable Development Policy Institute. Accessed June $3,2010$.

82. Khan JA. Multilateral Environmental Agreements. Presented at the LEAD Pakistan; 2007; Islamabad, Pakistan. http://www.lead.org.pk/c111nts/faculty\%20Presentation/Jawed\%20Ali\%20Khan.ppt. Accessed June 3,2010 .

83. The World Bank. Pakistan Strategic Country Environmental Assessment. South Asia Environment and Social Development Unit; 2006.

84. PM's speech on release of Climate Change Action Plan : Speeches : Prime Minister of India - Dr. Manmohan Singh (May 22, 2004 - 26th May 2014). Accessed March 1, 2019.

85. Deen MYI. Islamic Environmental Ethics. In: Ethics of Environment and Development. London: Belhaven Press; 1990.

86. Wilson HH. Rig-Veda-Sanhitā: A Collection of Ancient Hindu Hymns. Cosmo Publications; 1977.

87. Bryant E. The Quest for the Origins of Vedic Culture: The Indo-Aryan Migration Debate. Oxford University Press; 2001.

88. Lal BB. Homeland of the Aryans: Evidence of Rigvedic Flora and Fauna \& Archaeology. New Delhi: Aryan Books International; 2005.

89. Budholai B. Environment Protection Laws in the British Era. Published 2009.
Citation: Bhandari MP. "BashudaivaKutumbakkam"- The entire world is our home and all living beings are our relatives. Why we need to worry about climate change, with reference to pollution problems in the major cities of India, Nepal, Bangladesh and Pakistan. Adv Agr Environ Sci. (2019);2(I): 8-35. DOI: 10.3088I/aaeoa.000I9 
90. Chandra M. Environmental Concerns in India: Problems and Solutions. $J$ Int Bus Law. 2015;15(1).

91. Asian Development Bank (ABD). India: Country Partnership Strategy 2013-2017.; 2013.

92. Irfan U. How Delhi became the most polluted city on Earth. Vox. Published November 22, 2017. Accessed March 1, 2019.

93. Huizhong W. 75\% of India's air pollution-related deaths are rural. CNN Accessed March 1, 2019.

94. Heanue S. India's air pollution crisis risks becoming humanitarian catastrophe. Published February 24, 2018.

95. Divan S, Rosencranz A. Environmental Law and Policy in India. 2nd ed. New Delhi ; New York: OUP India; 2002.

96. Indian National Science Academy. Pursuit and Promotion of Science: The Indian Experience. New Delhi: Indian National Science Academy; 2001.

97. Gadgil M, Guha R. Ecological conflicts and the environmental movement in India. Environ Issues India Read. 2007:420.
98. Delhi. Government has Taken Series of Steps to Address Pollution-Related Issues: Environment Minister. Business Standard India. Published July 19, 2016. Accessed March 1, 2019.

99. India plants 66 million trees in 12 hours as part of record-breaking environmental campaign | The Independent. Accessed March 1, 2019.

100. 6 Important Eco-friendly Steps Taken By Narendra Modi Government Skymet Weather Services. Accessed March 1, 2019.

101. Kishwan J, Pandey D, Goyal AK, Gupta AK. India's Forests. New Delhi: Ministry of Environment and Forests, Government of India; 2007.

102. Government of India. India's major donors and collaborative partners in addressing the environment and climate change issues. Accessed May 2, 2010 .

103. United Nations. Economic and Social Survey of Asia and the Pacific. New York; 2000.

104. South Asian Association for Regional Cooperation (SAARC).

105. Bhandari MP. Green Web-II: Standards and Perspectives from the IUCN. River Publishers; 2018. 